\title{
A Case Study of Cyclic Top Coal Weakening Process Based on Highly Tough Coal Seam with Partings
}

\author{
Zhaopeng Wu, ${ }^{1}$ Junhui Wang ${ }^{1},{ }^{1}$ Zhijun Wan ${ }^{D},{ }^{1}$ Jingyi Cheng, ${ }^{1}$ Luchang Xiong, \\ Lizhu Zhao, ${ }^{2}$ and Xiaogang Liu $^{3}$ \\ ${ }^{1}$ Key Laboratory of Deep Coal Resource Mining (CUMT), Ministry of Education of China, School of Mines, \\ China University of Mining and Technology, Xuzhou, Jiangsu 221116, China \\ ${ }^{2}$ Yushutian Coal Mine, Xuzhou Coal Mining Group, Xuzhou, Jiangsu 221018, China \\ ${ }^{3}$ Xinjiang Branch, Xuzhou Coal Mining Group, Xuzhou, Jiangsu 221018, China
}

Correspondence should be addressed to Junhui Wang; wangjunhui@cumt.edu.cn and Zhijun Wan; zhjwan@cumt.edu.cn

Received 15 September 2020; Accepted 16 December 2020; Published 4 January 2021

Academic Editor: Guangchao Zhang

Copyright (C) 2021 Zhaopeng Wu et al. This is an open access article distributed under the Creative Commons Attribution License, which permits unrestricted use, distribution, and reproduction in any medium, provided the original work is properly cited.

\begin{abstract}
The top coal weakening process is an effective mean to increase the coal output, reduce the coal resource waste, and promote the sustainable development in a mine. The conventional blast weakening process and water injection weakening process are more widely applied in fully mechanized caving mining of hard thick coal seams, but under some special complex geological conditions, no desirable performance has been achieved in top coal weakening by one weakening process alone after substantial investment in capital and equipment. In the context of highly tough top coal with partings at working face 110501 for fully mechanized top coal caving mining in Yushutian Coal Mine, effects of parting band and high toughness on top coal breaking were studied in terms of mechanism and extent, a multifunctional compound drilling field integrating blast weakening, water injection weakening, and gas extraction was purposefully designed, and a cyclic top coal weakening process for highly tough coal seams with partings was proposed. Engineering practice and performance testing show that degree of fragmentation and mobility of top coal was improved, mean top coal recovery ratio at the working face increased by about $35 \%$, coal resource waste decreased, and potential risks of gas explosion and mine fire were eliminated, which provides reference for top coal weakening process under similarly complex engineering conditions.
\end{abstract}

\section{Introduction}

The fully mechanized sublevel caving method features high efficiency, simple production system, and strong adaptability to variations in coal seam thickness and is a common process for improving production efficiency and coal output at the working face $[1,2]$. However, subject to top coal structure [3], top coal cavability [4], refuse content of caved coal [5], etc., some top coals fail to be fully broken and caved, resulting in poor economic benefit of a mine and serious waste of coal resource [6] not in favor of sustainable mine development. In order to improve coal recovery ratio, top coal zone is usually preweakened prior to fully mechanized caving mining [7]. Common top coal weakening processes mainly include weakening by deep-hole presplit blasting
$[8,9]$ and coal seam weakening by water injection [10-12] and are more widely applied in fully mechanized caving mining of hard thick coal seams. Nonetheless, under special geological conditions such as highly tough coal seams with partings, it is difficult for the conventional top coal weakening process to break fully top coal, failing to achieve ideal weakening performance.

Arch structures forming out of thick and hard parting bands in the top coal [13] and nonfriable highly tough top coal [14] have serious impact on top coal weakening performance. Although remarkable progresses have been made in current research on top coal weakening process, scholars rarely studied the top coal weakening process featuring parting band and high toughness. Ma et al. $[14,15]$ studied the mechanism of caving difficulty of highly tough coal 
seams by numerical simulation and analog simulation, respectively, proposed top coal weakening schemes under corresponding geological conditions, and elucidated the inevitability of improving the top coal weakening process. By optimizing blasting parameters, Zhao [16] redesigned the top coal blast weakening process and improved the cavability of highly tough top coal and weakening performance of the top coal. Liao et al. [17] modified top coal weakening process by top coal water injection plus blasting, enabling technical breakthroughs in mining of hard coal seams with hard roofs, and provided reference for design and improvement of top coal weakening process under special geological conditions. In addition, more scholars $[6,18,19]$ studied the mechanism of parting band influencing top coal fragmentation and eliminated the impact of parting band on top coal caving by means of deep-hole presplit blasting so that top coal recovery ratio was increased and expected weakening performance was achieved. However, such studies do not involve design and modification of top coal weakening process in coexistence of parting band and high toughness, resulting in undesirable top coal weakening performance, poor mining efficiency, and fewer coal output.

One weakening method alone fails to weaken fully the highly tough top coal with partings. The conventional top coal weakening process by blasting was redesigned and set up again, and the arranged blast drilling field was repeatedly utilized to conduct gas extraction [20-22] and top coal weakening by water injection [23-26], resulting in a multifunctional, mutually promoting, and cyclic top coal weakening process, in order to maximize the economic benefit and optimize the top coal weakening performance. While increasing economic benefit of a mine and preventing it from mine fire [27] and gas explosion [28, 29], this process enabled less waste of coal resource and sustainable mine development.

In this study, it is believed that parting band and high toughness have serious impact on top coal cavability at working face 110501 in Yushutian Coal Mine, and thus the original top coal weakening process has to be modified correspondingly. Firstly, mechanism and extent of the parting band and high toughness influencing top coal fragmentation at working face 110501 were investigated by means of numerical simulation and theoretical computing, respectively. Secondly, the original top coal weakening process was modified and specially designed; thereby, a cyclic top coal weakening process suitable for highly tough coal seam with partings was proposed and applied in engineering practice. By integrating blast weakening, water injection weakening, and gas extraction, this process enabled full top coal weakening and rapid gas extraction. Finally, performance of the cyclic top coal weakening process was tested and assessed in terms of mean degree of borehole fragmentation, cumulative top coal displacement, and top coal recovery ratio.

\section{Engineering Geological Conditions}

2.1. Study Area and Mining Setup. Yushutian Coal Mine, located in the Xinjiang Uygur Autonomous Region, China, was selected as the study area. Fully mechanized sublevel caving face 110501 is the first mining face of this mine (e.g., in Figure 1(a)), and mining was conducted in coal seam No. 5. The average seam thickness, face length, and strike length are $9.5 \mathrm{~m}$ (mechanized mining height: $3 \mathrm{~m}$ ), $170 \mathrm{~m}$, and $1580 \mathrm{~m}$, respectively. The coal seam has high gas content $(0.17-1.68 \mathrm{~mL} / \mathrm{g})$ where gas drainage and extraction are very difficult. During initial mining at the working face, it was difficult to break and cave the top coal, as the large lump rate (equivalent size of residual coal $>$ size of coal caving mouth) was as high as $40 \%$ (e.g., in Figure 1(b)) and the mean top coal recovery ratio was less than $50 \%$ (e.g., in Figure 1(c)); the uncaved top coal fell along with the roof to the goaf and could no longer be mined [6], leading to huge waste of coal resource. Moreover, a great amount of residual coal in the goaf will pose fire hazard to the mine, too.

\subsection{Causal Investigation for Low Recovery Ratio of Top Coal.} Causal investigation for the low recovery ratio of top coal at working face 110501 shows that roof occurrence condition and top coal nature are main causes of low recovery ratio, and top coal weakening process has to be further optimized.

Firstly, external factors influence top coal caving. According to key strata distinguishing theory [30], there are 5 thick hard key strata above the top coal (e.g., in Figure 2(a)). The complex structure (e.g., in Figure 2(b)) enabled great reduction in the action of overlying strata breaking pressure on the top coal [31]. Based on field survey of the working face, periodic weighting interval was great and roof weighting was insignificant (e.g., in Figure 2(c)); hence, the long hanging roof failed to crush and break the top coal effectively.

Secondly, intrinsic factors influence top coal caving, too. The field survey revealed two thick parting bands $(0.64 \mathrm{~m}$ and $0.37 \mathrm{~m}$ thick, respectively) within the top coal (e.g., in Figure 2(d)), and presence of partings further precluded top coal fissures from development and connection [6]. In addition, mechanical test of coal samples show that coal seam No. 5 belongs to highly tough coal (elastic modulus $<2 \mathrm{GPa}$, prepeak deformation $>0.015$, and ratio of compressive strength to tensile strength $<16$ ) [15] (e.g., in Figure 2(e)), implying strong energy storage capacity and plastic deformation capability of top coal, rendering the top coal not prone to brittle fracture $[14,32]$. Hence, two intrinsic factors of top coal, namely, parting band and high toughness, affected jointly top coal cavability.

Finally, the top coal could not be well weakened by original top coal weakening process, i.e., common deep-hole presplit blasting (e.g., in Figure 2(f)), in which blast boreholes varying in depth and dip angle are arranged outside crossheading abutment pressure influence zone to conduct blast presplitting of top coal. Although this process is widely applied $[8,19,21,33,34]$, it does not focus on high toughness and parting characteristics of the top coal at working face 110501, resulting in insignificant weakening performance.

The above three causes were discussed here. Occurrence of overlying strata in this mine is very complex, and with existing technology, it is very difficult to control precisely 


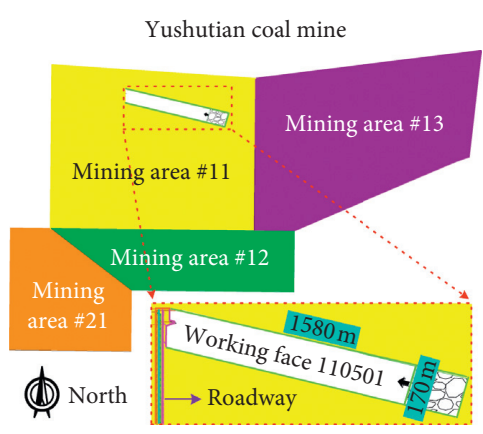

(a)

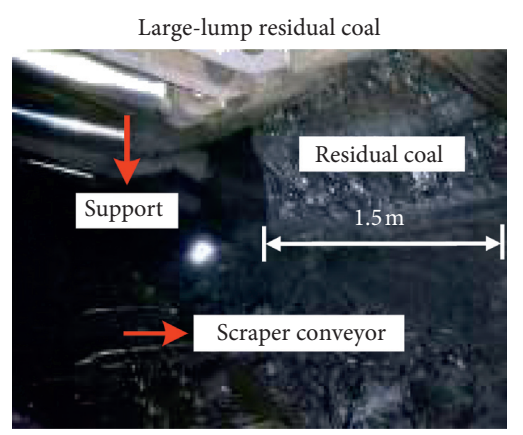

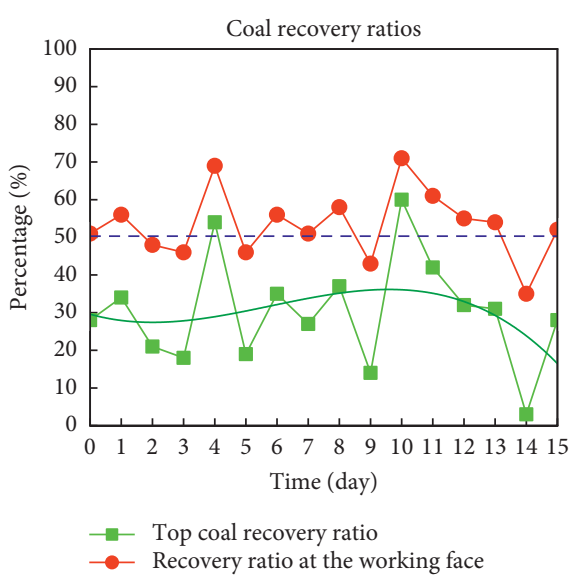

(c)

FIgURE 1: Engineering geological conditions. (a) Mining setup. (b) Large-lump residual coal in the goaf. (c) Coal recovery ratios.

\begin{tabular}{|c||c|}
\hline \multicolumn{2}{|c|}{ Overlying strata } \\
\hline & Topsoil \\
\hline $34.9 \mathrm{~m}$ & Key stratum \\
\cline { 2 - 2 } & Soft rock \\
\hline & Key stratum \\
\hline $44.4 \mathrm{~m}$ & Soft rock \\
\hline & Key stratum \\
\hline & Soft rock \\
\hline & Key stratum \\
\hline & Soft rock \\
\hline $15.1 \mathrm{~m}$ & Key stratum \\
\hline \hline $15.2 \mathrm{~m}$ & Soft rock \\
\hline & Basic roof \\
\hline & Immediate roof \\
\hline \hline
\end{tabular}

(a)

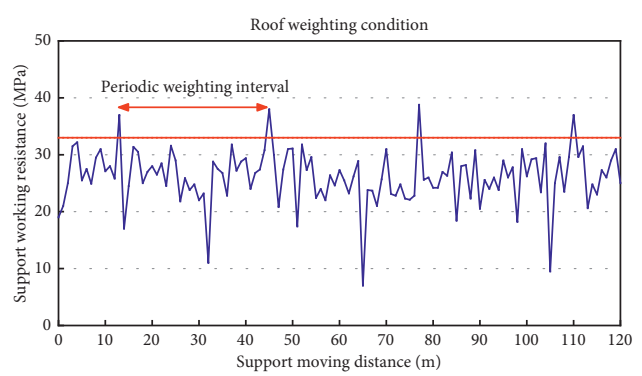

- Time-weighted average working resistance

(c)

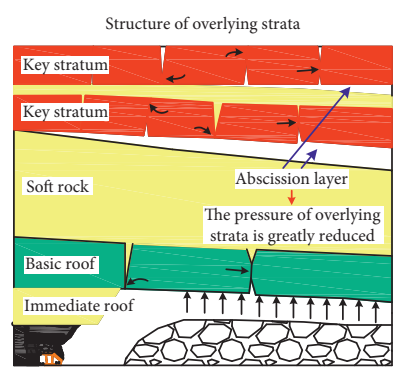

(b)

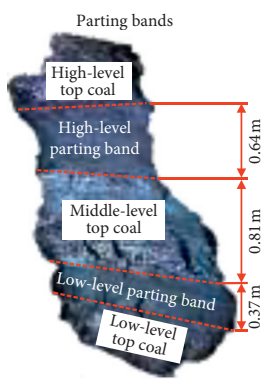

(d)

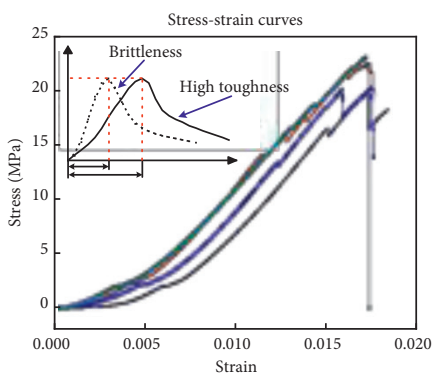

(e)

Figure 2: Continued. 


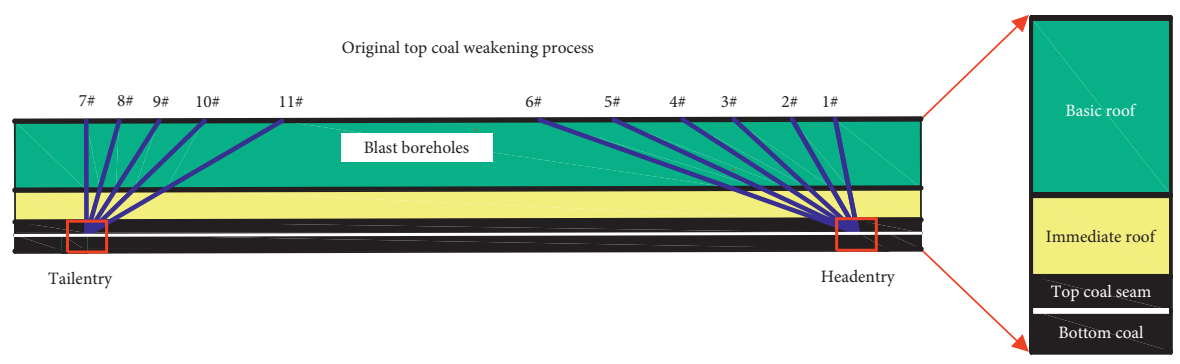

(f)

FiguRE 2: Causal investigation for low recovery ratio of top coal. (a) Occurrence of overlying strata. (b) Structure of overlying strata. (c) Roof weighting condition. (d) Positions and thicknesses of parting bands within the top coal. (e) Stress-strain curves for highly tough top coal, where elastic modulus was $1.73 \mathrm{GPa}$, prepeak deformation was 0.017 , and ratio of compressive strength to tensile strength was 10.68 . (f) Layout of blast boreholes in the original top coal weakening process.

pressure transfer from the roof to caved portion of top coal by altering the stratum structure [35-38], and it is prone to ground subsidence $[39,40]$, bringing more technical troubles and economic burden to mine production. Thus, it is not feasible to improve the recovery ratio of top coal from perspective of external factors. Instead, the authors mainly studied rationale of the extent of impact of two intrinsic factors, parting band and high toughness, on top coal fragmentation, and thereby designed purposefully a top coal weakening process for working face 110501. The authors strived to enable sustainable mine development with less coal resource waste and good economic benefit.

\section{Rationale}

\subsection{Modeling}

3.1.1. Self-Supporting Model for Partings in Top Coal. For parting bands in top coal, number of bands, thickness, strength, position, and other factors will influence top coal fragmentation $[6,41]$. The stressed state of the parting bands in top coal can be estimated according to occurrence of parting bands inside working face 110501 in Yushutian Coal Mine, and the extent of impact of both parting bands (e.g., in Figure $2(\mathrm{~d})$ ) on top coal fragmentation can be determined by theoretical computing. A parting band can be simplified as a cantilever beam model under uniform load (e.g., in Figure 3(b)) because of abscission layer [41-43]. The top coal above the high-level parting band serves as a load on the high-level parting band because of advanced deformation of the top coal above the parting band and presence of roof abscission layer, while the top coal overlying the low-level parting band serves as a load on the low-level parting band because of an abscission layer between the top coal overlying the low-level parting band and the high-level parting band (e.g., in Figure 3(a)).

3.1.2. Blasting Model for Highly Tough Top Coal. High toughness of coal is mainly manifested as low elastic modulus of coal [15]; the elastic modulus of coal seam No. 5 in Yushutian Coal Mine is $1.8 \mathrm{GPa}$, which belongs to highly tough coal (elastic modulus $<2 \mathrm{GPa}$ ). Therefore, the LSDYNA program can be used to establish the blasting model of highly tough top coal. LS-DYNA is a universal explicit dynamic analysis program for simulation of fissure propagation after deep-hole blasting. Based on physical mechanical parameters of top coal at working face 110501 in Yushutian Coal Mine, a numerical model for single-hole coal blasting was created, and nonreflection boundaries and boundary stress equivalent to confining pressure were set up. The blasting model is $6 \mathrm{~m}$ long by $6 \mathrm{~m}$ wide, the charge structure is uncoupled charge with a clearance reserved between the explosive cartridge and the blasthole wall [44], blasthole diameter is $75 \mathrm{~mm}$, explosive diameter is $60 \mathrm{~mm}$, and five measurement points are arranged at distances of $0.5 \mathrm{~m}, 1 \mathrm{~m}, 1.5 \mathrm{~m}, 2 \mathrm{~m}$, and $3 \mathrm{~m}$ away from the blasthole center, respectively (Figure 4).

\subsection{Modeling Results}

3.2.1. Self-Supporting of Partings in Top Coal. Effects of thickness, tensile strength, and compressive strength of a parting band in top coal and thickness of its overlying coal seam on computing results were mainly considered. To the knowledge of material mechanics, the bending moment of a parting cantilever beam is

$$
M_{A}=\frac{q l^{2}}{2}=\frac{\left(q_{1}+q_{2}\right) l^{2}}{2}
$$

and tensile stress of the parting cantilever beam is

$$
\sigma=\frac{6 M_{A}}{h^{2}}=\frac{3 q l^{2}}{h^{2}} .
$$

The maximum negative moment occurs at the junction between the parting band and coal wall (Figure 5).

Then, the tensile stress at the junction is the maximum:

$$
\sigma_{\max }=\frac{6 M_{\max }}{h^{2}}=\frac{3\left(\gamma_{1} h_{1}+\gamma_{2} h_{2}\right) l^{2}}{h^{2}} \text {. }
$$

Let the maximum length of the parting band cantilever be $1 \mathrm{~m}$ in order to ensure safety of top coal caving. It is known from equation (3) that, given a fixed parting band cantilever length $l$, tensile stress increases with decreasing cantilever beam thickness $h$, indicating that the smaller the 


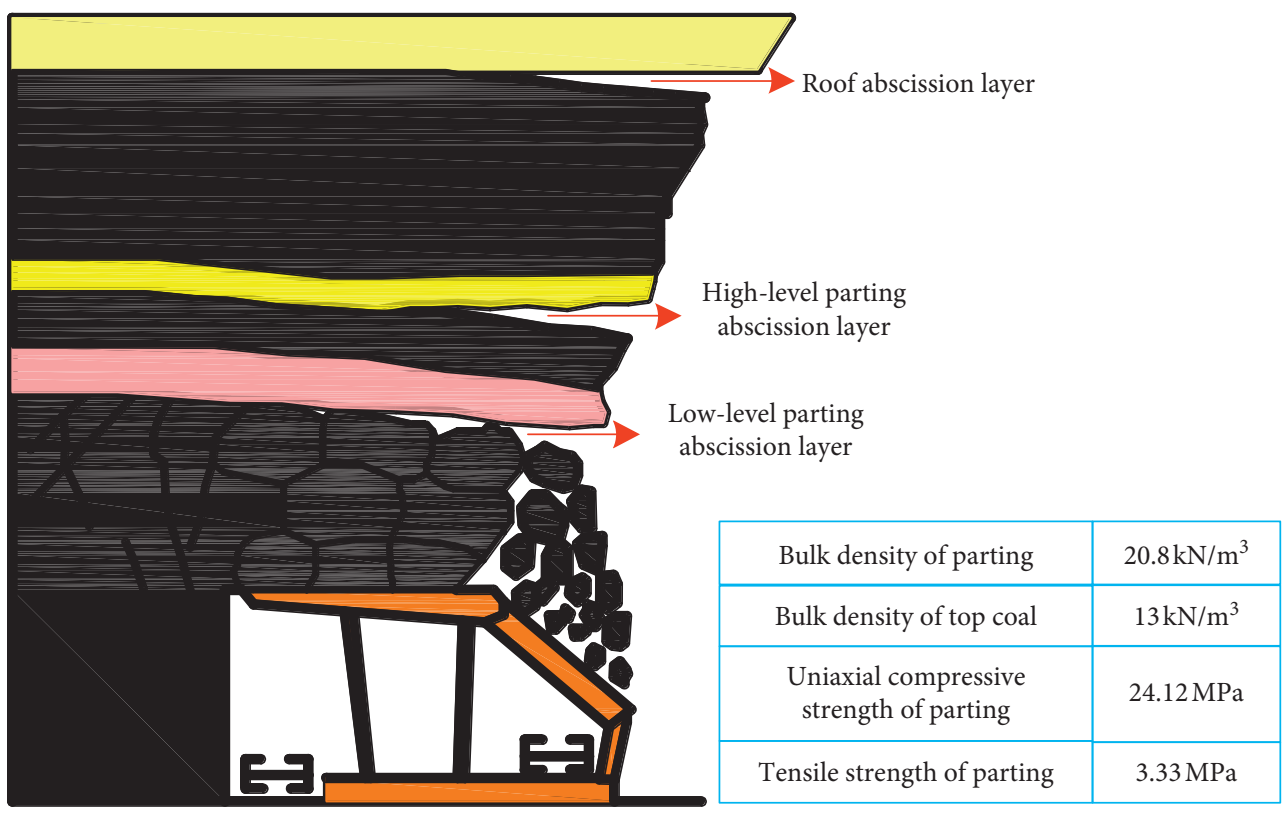

(a)

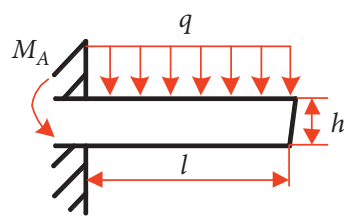

(b)

FIGURE 3: Mechanical analysis model for partings in top coal. (a) Stressed state of parting bands. (b) Cantilever beam model for parting band under uniform load.

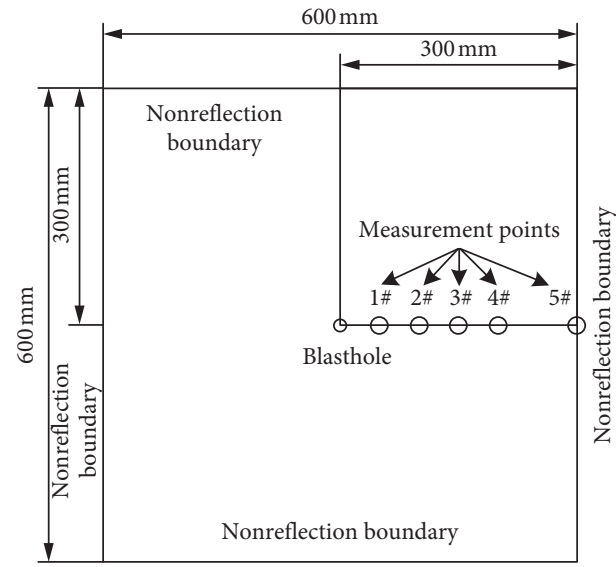

Figure 4: Blasting simulation model.

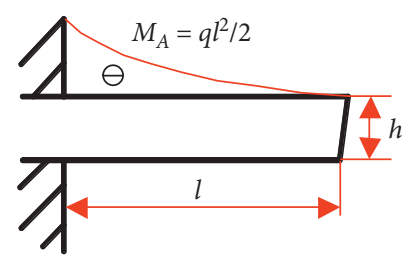

FIGURE 5: Bending moment of cantilever beam under uniform load.

parting thickness, the more prone it is to destruction of the parting band. Therefore, a critical parting band thickness without fracturing is present when overlying coal seam thickness and permissible cantilever beam overhang length are given. Let the maximum tensile stress $\sigma_{\max }$ be equal to tensile strength $R_{t}$ of the parting, critical thickness of a parting band can be obtained:

$$
h_{\min }=\frac{3 l^{2} \gamma_{1}+\sqrt{9 l^{4} \gamma_{1}^{2}+120 l^{2} \gamma_{2} h_{2} R_{t}}}{2 R_{t}} .
$$

Substituting values into corresponding parameters in equation (4), one can solve for corresponding critical parting band thicknesses when thickness of coal seam overlying the parting band is $0-4 \mathrm{~m}$ (Figure 6).

When the thickness of the coal seam overlying the highlevel parting band is $3 \mathrm{~m}$, it can be determined from Figure 6 that critical thickness of the high-level parting band is about $0.6 \mathrm{~m}$, less than actual thickness (e.g., in Figure 2(d)) of the high-level parting band $(0.64 \mathrm{~m})$, so it is difficult to break the high-level parting band and an abscission layer forms between it and its underlying coal seam. The region underneath the abscission layer becomes a new cantilever structure because of the abscission layer, and $0.81 \mathrm{~m}$ thick coal seam between parting bands becomes a coal seam overlying the low-level parting band. It can be determined from Figure 6 that critical thickness of the low-level parting band is about $0.32 \mathrm{~m}$, less than actual thickness (e.g., in Figure $2(\mathrm{~d}))$ of the low-level parting band $(0.37 \mathrm{~m})$, so it is also difficult to break the low-level parting band.

As known from computing results, two thick parting bands within top coal at working face 110501 affected top coal cavability. On one hand, subject to number of parting bands, thickness, strength, position, and other factors, the partings are not prone to breaking and thus form cantilever structures inside the top coal, supporting the top coal above the partings so that the top coal is not prone to caving. On the other hand, even if top coal collapses, the presence of 


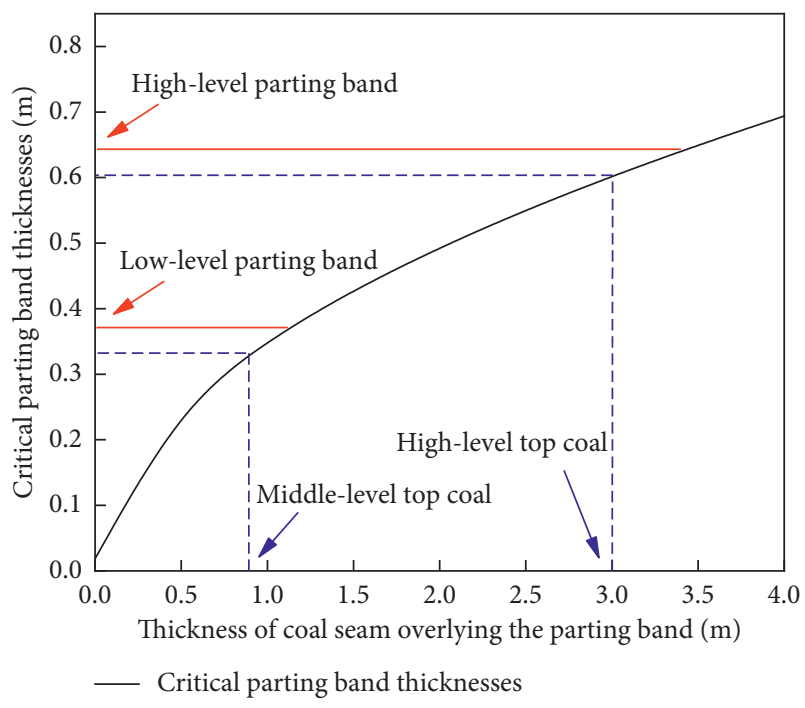

Figure 6: Curve of critical parting band thickness versus thickness of coal seam overlying parting band.

partings will result in greater lumpiness of the caved coal, which affects mobility of top coal during caving, making coal caving mouth of the hydraulic support more readily blocked so that the top coal cannot be caved. Therefore, special measures must be taken to break the parting bands.

\subsubsection{Effect of High Toughness of Top Coal on Blast} Weakening. The blast weakening process can be justified by studying development of fissures in top coal with low elastic modulus after blast weakening. Hence, the extent of impact of high toughness on fissure development in top coal was investigated by comparing coal fissure development versus elastic modulus. When elastic modulus of the blasting simulation model was set to $1.8 \mathrm{GPa}, 10 \mathrm{GPa}, 20 \mathrm{GPa}$, or $30 \mathrm{GPa}$, ultimate fissure development in the blasted coal was observed (Figure 7). In these cases, the simulated result in Figure 7(a) is the field case of Yushutian Coal Mine.

Curves of stress wave propagation velocity, fissure propagation velocity, pressure at model boundary, and crushing circle radius versus elastic modulus (Figure 8) are plotted based on simulation results and data (Table 1).

Four parameters, namely, stress wave propagation velocity, fissure propagation velocity, pressure at model boundary, and crushing circle radius, are closely related to fissure development after blast weakening of top coal [19]. It is found from numerical simulation results (Figure 7) and the curves in Figure 8 that, as elastic modulus increases, propagation velocity of explosion stress wave in coal, fissure growth velocity, and coal pressure at the same position increase accordingly, and given an elastic modulus not higher than $20 \mathrm{GPa}$, crushing circle radius increases gradually with increasing elastic modulus, too.

From perspective of fissure distribution, at four elastic moduli, fissures could propagate to boundaries, but inside the highly tough top coal (e.g., at an elastic modulus of $1.8 \mathrm{GPa}$ ), dominant fissures were markedly fewer, fissure density was lower, secondary fissures grew more slowly, and blast induced damage and fragmentation to smaller extent. Therefore, it is believed that high toughness of top coal has serious impact on fissure development in top coal at working face 110501, the blast weakening process alone fails to meet the requirement for full fragmentation of top coal, and the process has to be optimized.

\section{Engineering Practice}

4.1. Cyclic Top Coal Weakening Process. The hybrid blastwater injection weakening process enables effective improvement of top coal weakening performance and, along with gas extraction process, is able to eliminate potential risks of mine fire and gas explosion while bringing huge economic benefit. In order to improve weakening performance of highly tough top coal with partings, based on rationalization of existing coal mining facilities in the coal mine, a multifunctional compound drilling field that can be used in blast weakening, water injection weakening, and gas extraction was designed, and a cyclic top coal weakening process was proposed. Each compound drilling field controls a drilling and blasting area (e.g., in Figure 9(a)), and a number of multifunctional compound drilling fields work pairwise in cycles to conduct sublevel weakening of the top coal (e.g., in Figure 9(b)). This process enables rapid extraction of gas while weakening fully high-toughness top coal with partings [45].

Flowchart of the cyclic top coal weakening process is shown in Figure 10. Firstly, compound drilling fields for high-level top coal blasting are designed and arranged, and blastholes are attached tightly to parting bands that are then fully broken by blasting, leading to initiation of fissures in the top coal and initial weakening of the top coal. Secondly, the compound drilling fields are utilized again to arrange gas extraction boreholes once every drilling field, and gas disturbance by stress wave and fissure network generated in the blasted top coal are employed to enable high-performance gas extraction in coal seam [20-22]. Finally, the compound drilling fields and gas extraction boreholes are used again to perform dynamic and static water injection to allow for further propagation and connection of fissures [10] so that the top coal is fully weakened. Full weakening of top coal can be achieved by repeating the above three steps in the direction of working face advancing at the rate of working face advancement, thereby coal recovery ratio can be greatly increased. As water injection into a coal seam will inhibit gas desorption in the coal seam [23-26], it should be noted to conduct gas extraction first and then water injection to weaken the coal seam.

4.2. Arrangement of Multifunctional Compound Drilling Fields. Multifunctional compound drilling fields should be arranged in ground stress zone. Arrangement of blast drilling fields in abutment pressure elevation zone leads to serious borehole deformation and difficulties in drilling and charging, thus secondary fragmentation effect of abutment pressure cannot be well utilized to weaken top coal $[46,47]$. If compound drilling fields are arranged in ground stress 

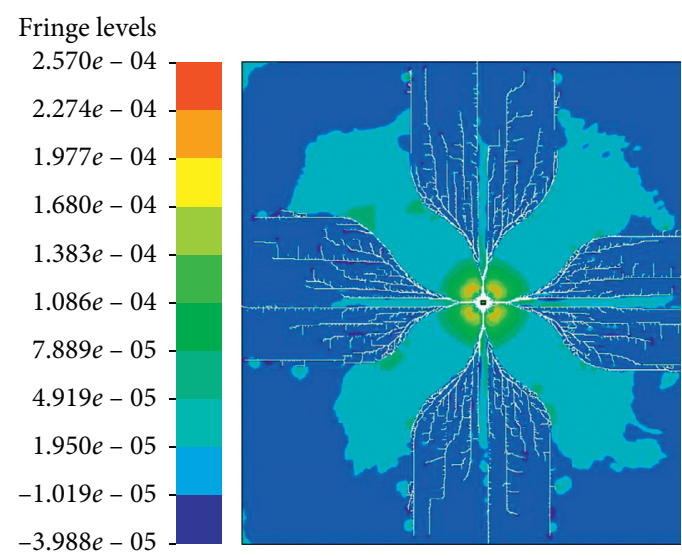

(a)

Fringe levels

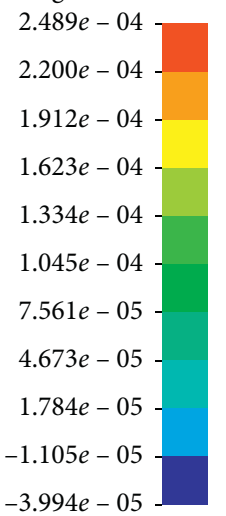

$-3.994 e-05$

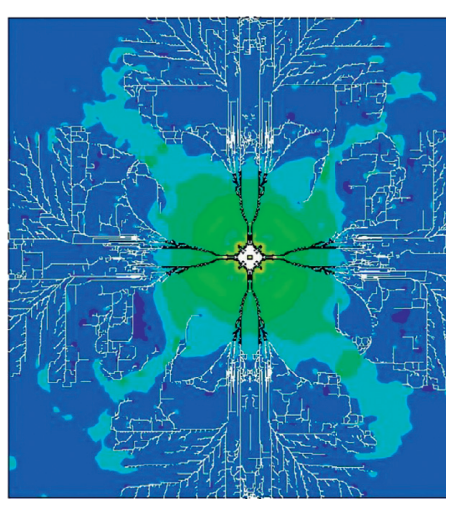

(c)

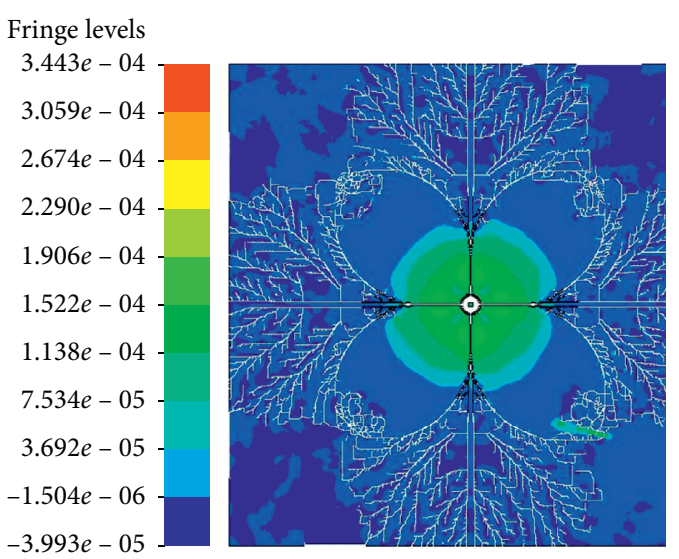

(b)

Fringe levels

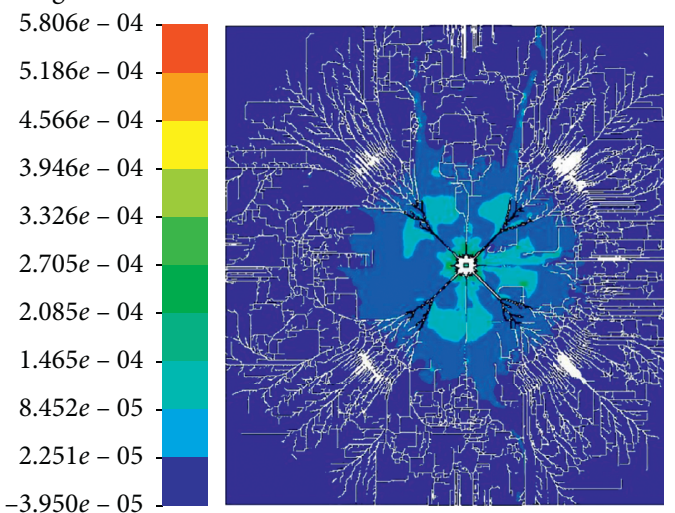

(d)

Figure 7: Ultimate fissure development in coal versus elastic modulus. (a) $E=1.8 \mathrm{GPa}$. (b) $E=10 \mathrm{GPa}$. (c) $E=20 \mathrm{GPa}$. (d) $E=30 \mathrm{GPa}$.

zone (e.g., in Figure 11(a)), then the drilling, charging, and blasting steps will stay away from influence of advanced abutment pressure at the working face. In order to avoid the impact of parting bands on top coal weakening performance, the authors designed specially a compound drilling field of $5 \mathrm{~m}$ (length) $\times 4 \mathrm{~m}$ (width) $\times 3.5 \mathrm{~m}$ (height), where boreholes are arranged in proximity to two parting bands (e.g., in Figure 11(b)) after parting band positioning, 1/3 of total length of each borehole is set as borehole closure area while the remaining $2 / 3$ is set as borehole charge area, and three $0.1 \mathrm{~m}$ long air columns are reserved at the bottom of each borehole (e.g., in Figures 11(c) and 11(d)) [48].

A compound drilling field controls a rectangular area of $80 \mathrm{~m}$ (length) $\times 54 \mathrm{~m}$ (width) within the drilling and blasting area. Each drilling and blasting area is divided into three different charge subzones (e.g., in Figure 12(a)), and 22 boreholes are arranged in the drilling field in a two-row triangular fashion with a spacing of $0.82 \mathrm{~m}$ between two rows of boreholes (e.g., in Figure 12(b)) to complete borehole arrangement in the multifunctional compound drilling field.

\subsection{Charging and Detonation in Compound Drilling Field.} The compound drilling field was charged and detonated to enable initial weakening of top coal. Boreholes in charge subzones \#1, \#2, and \#3 in the drilling and blasting area were charged at charge weights of $3.2 \mathrm{~kg} / \mathrm{m}, 2.8 \mathrm{~kg} / \mathrm{m}$, and $2.4 \mathrm{~kg} /$ $\mathrm{m}$ from hole bottom to hole top in the forward direction, respectively, and each borehole was packed at $1 / 3$ of borehole length near the hole top [18]. After being charged, all blastholes were denotated with blasting caps and blasted by a time delay in milliseconds such that fissures in coal developed gradually and connected to each other where possible (Figure 13). In blasting, boreholes were detonated in turn from the side approaching the working face towards the side away from the working face.

4.4. Rapid Gas Extraction. After blasting, gas extraction boreholes were arranged and the drilling field was utilized again to extract gas from top coal. It must be ensured that there should be one extraction borehole every other compound drilling field and bottom of each extraction borehole should be made to face the goaf (Figure 14), and the gases in current drilling and blasting area and the last neighboring drilling and blasting area will be mainly extracted while interaction between gas extraction in current field and blasting in the next drilling field $[21,28,49]$ should be prevented from borehole connection. 


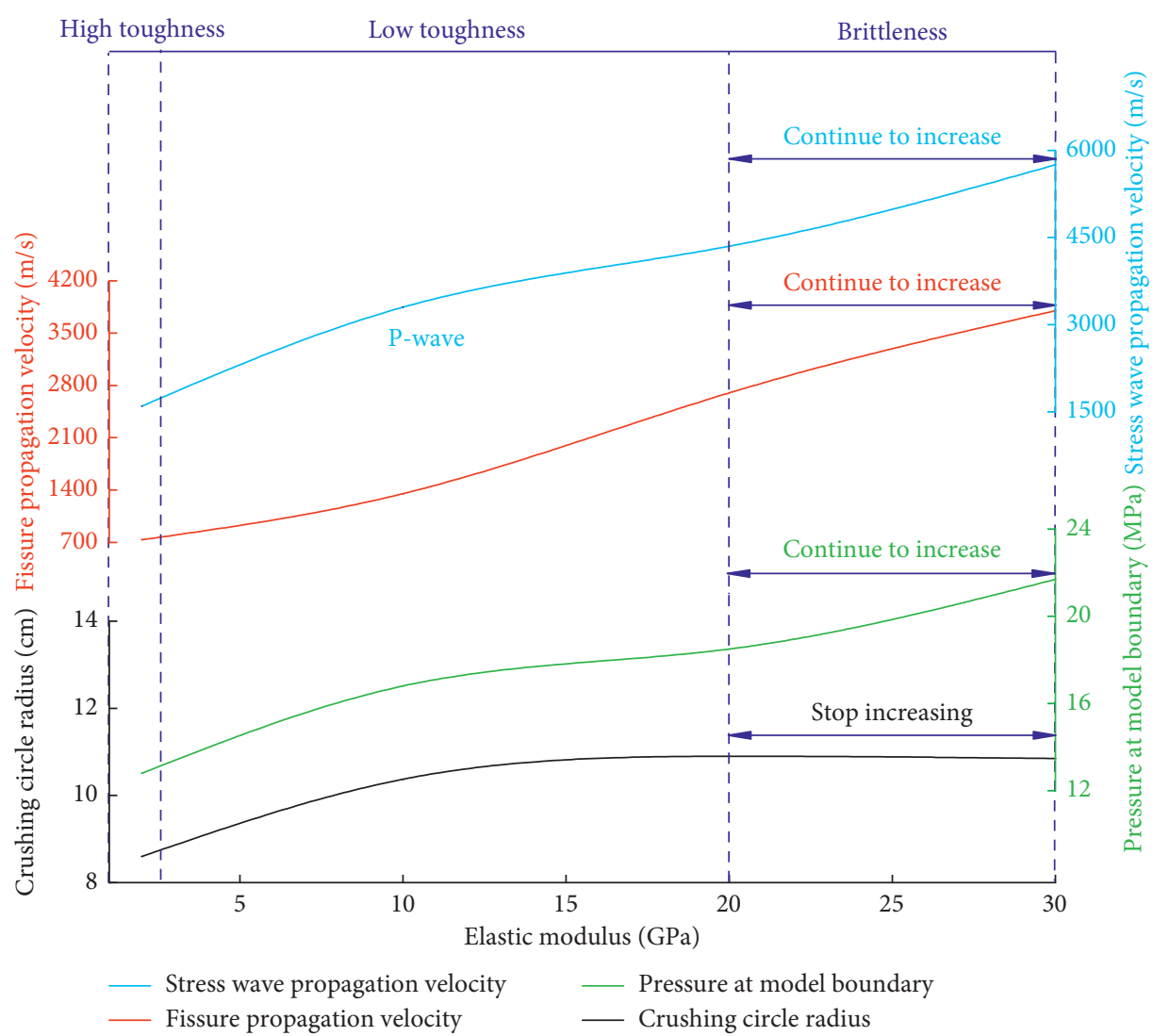

FIGURE 8: Curves of stress wave propagation velocity, fissure propagation velocity, pressure at model boundary, and crushing circle radius versus elastic modulus.

TABLe 1: Data after blasting for four kinds of elastic modulus derived from LS-DYNA program.

\begin{tabular}{lcccc}
\hline $\begin{array}{l}\text { Elastic modulus } \\
(\mathrm{GPa})\end{array}$ & $\begin{array}{c}\text { Time of stress wave } \\
\text { propagation }(\mu \mathrm{s})\end{array}$ & $\begin{array}{c}\text { Time of fissure } \\
\text { propagation }(\mu \mathrm{s})\end{array}$ & $\begin{array}{c}\text { Pressure at the model } \\
\text { boundary }(\mathrm{MPa})\end{array}$ & $\begin{array}{c}\text { Crushing circle radius } \\
(\mathrm{cm})\end{array}$ \\
\hline 1.8 & 950 & 4350 & 12.8 & 8.6 \\
10 & 930 & 1800 & 16.9 & 10.4 \\
20 & 680 & 1200 & 18.4 & 11 \\
30 & 560 & 860 & 20.6 & 11 \\
\hline
\end{tabular}

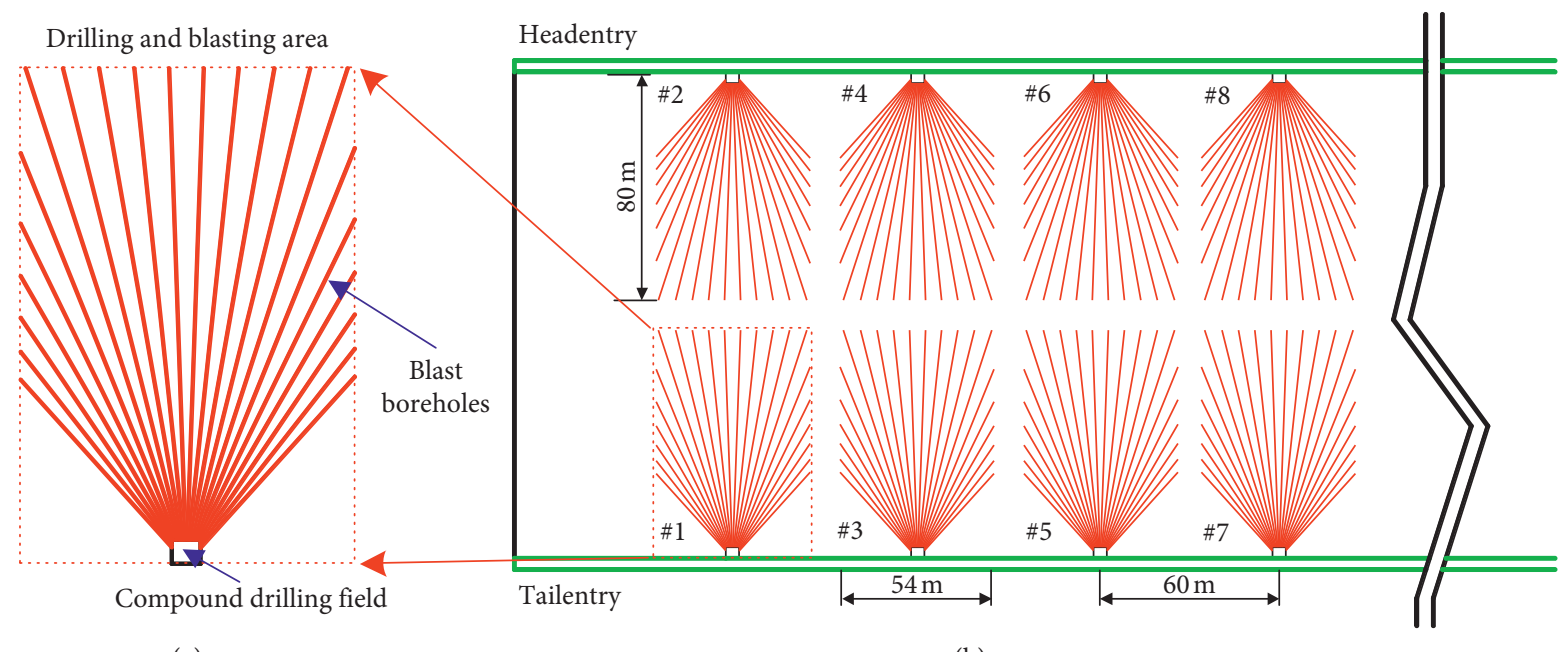

(a)

(b)

FIGURE 9: Design and arrangement of compound drilling fields. (a) Schematic diagram of drilling and blasting area. (b) Layout of compound drilling fields. 


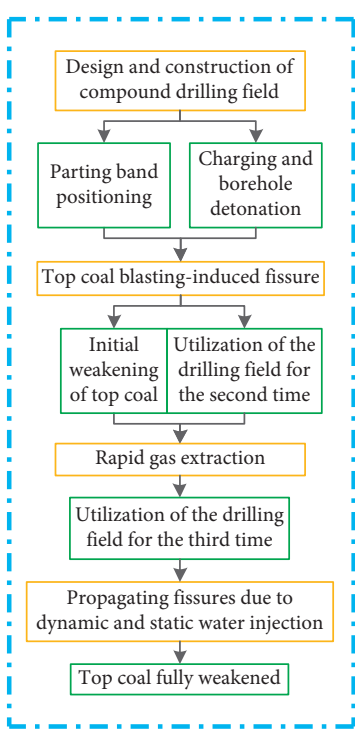

Drilling and blasting areas 1 and 2

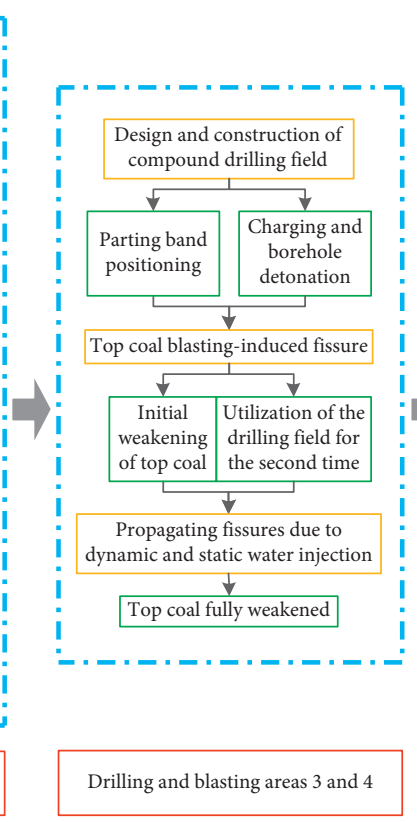

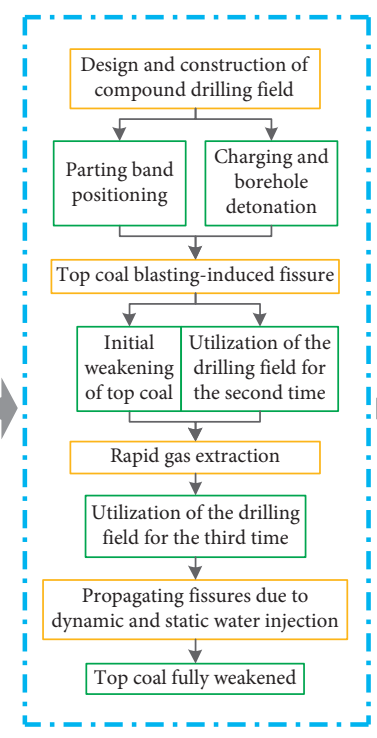

Drilling and blasting areas 5 and 6

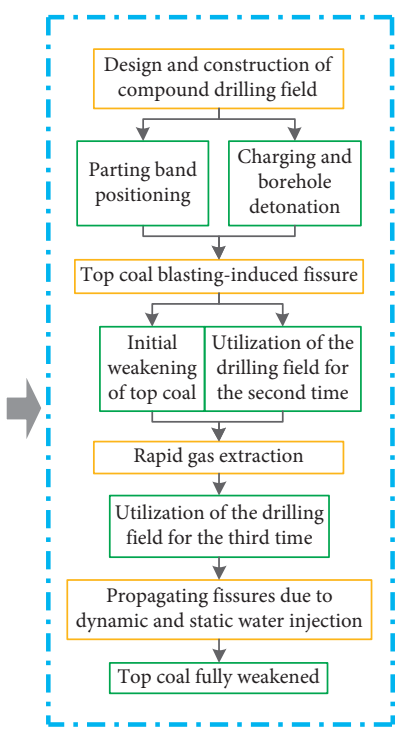

Drilling and blasting areas $\mathrm{n}$ and $(\mathrm{n}+1)$

Figure 10: Flowchart of the cyclic top coal weakening process.

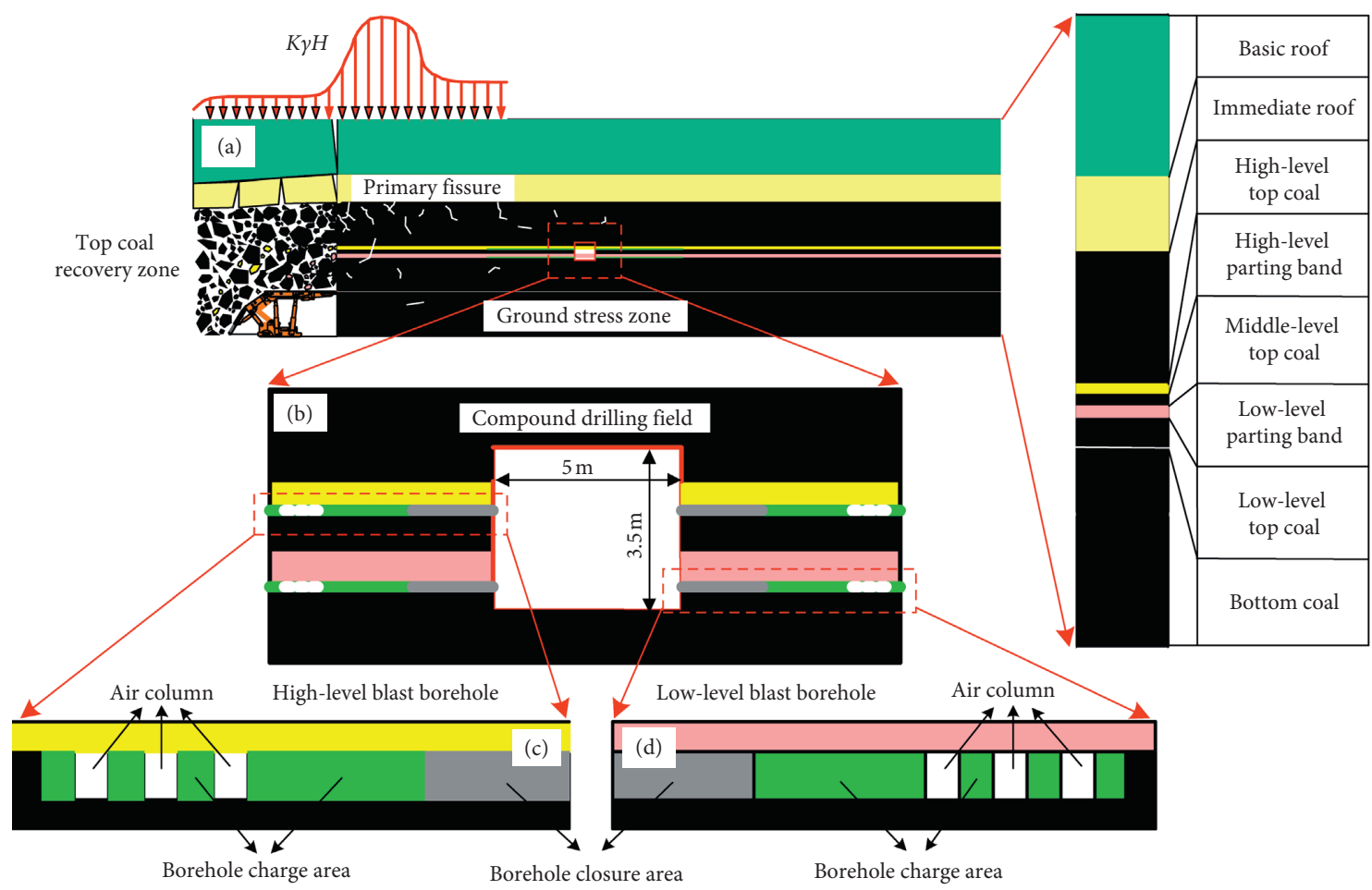

FiguRE 11: Schematic diagrams of compound drilling field and borehole design. (a) Locations of compound drilling fields. (b) Design schematic of a compound drilling field. (c) Schematic diagram of a high-level blast borehole. (d) Schematic diagram of a low-level blast borehole.

4.5. Dynamic and Static Water Injection. After gas extraction, the drilling field was for static water injection when pressure release phenomenon occurred. Water injection lasted for $48 \mathrm{~h}$, and while the coal was softened, existing fissures further propagated and were connected to enable full weakening of the top coal (Figure 15).

\section{Effect of Application}

5.1. Mean Degree of Borehole Fragmentation. Mean degree of borehole fragmentation is a direct representation of the extent of top coal fragmentation. The YTJ20 mine electronic borehole observation apparatus, along with casing pipes, was 


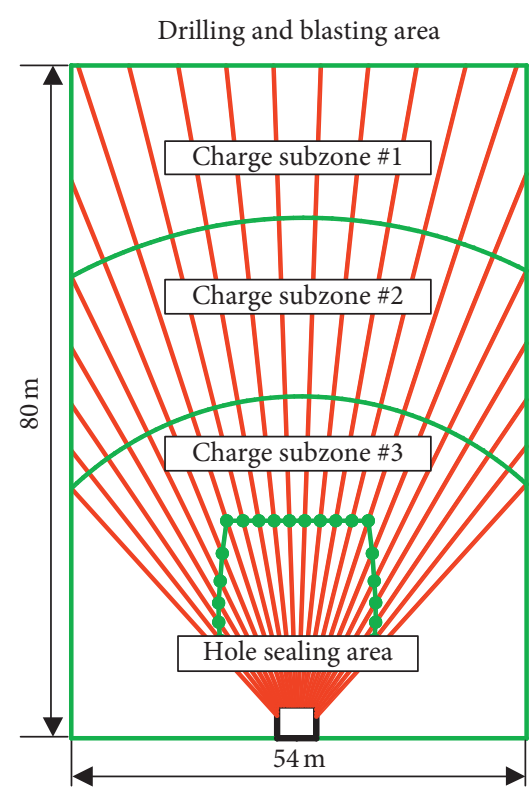

(a)

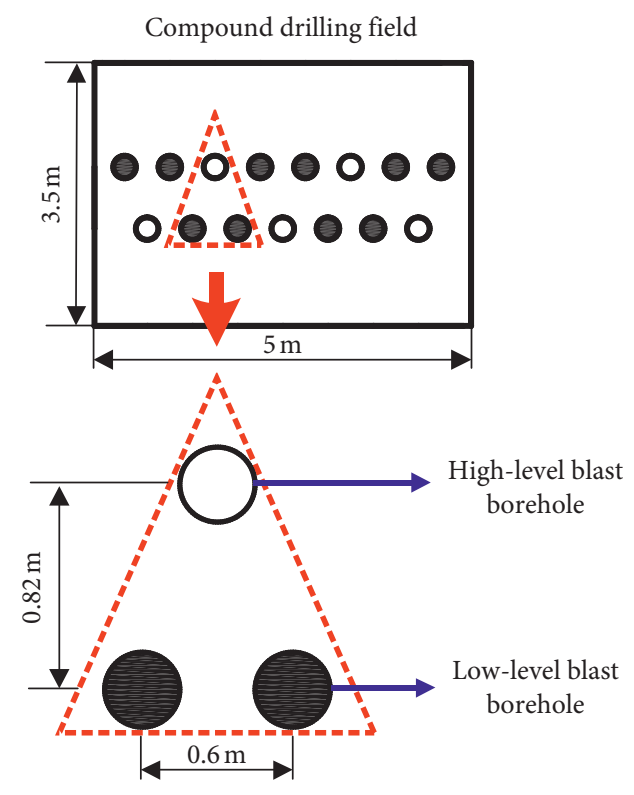

(b)

FIGURE 12: Schematic diagrams of borehole arrangement in compound drilling field. Schematic diagram of (a) charge subzones in drilling and blasting area and (b) boreholes arranged in a two-row triangular fashion.

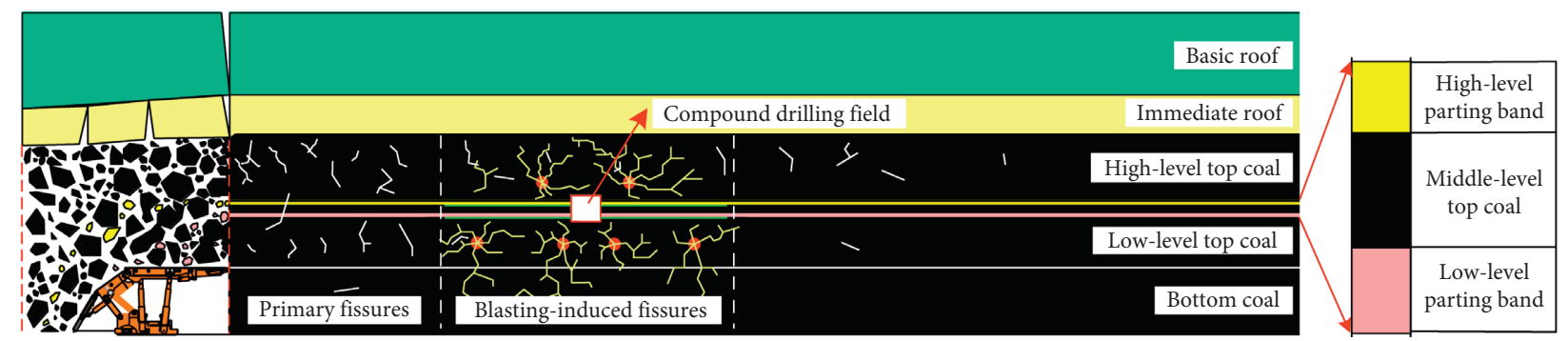

Top coal recovery zone

Drilling and blasting areas 1 and 2

FIgURE 13: Schematic diagram of fissure development in top coal weakened by blasting.
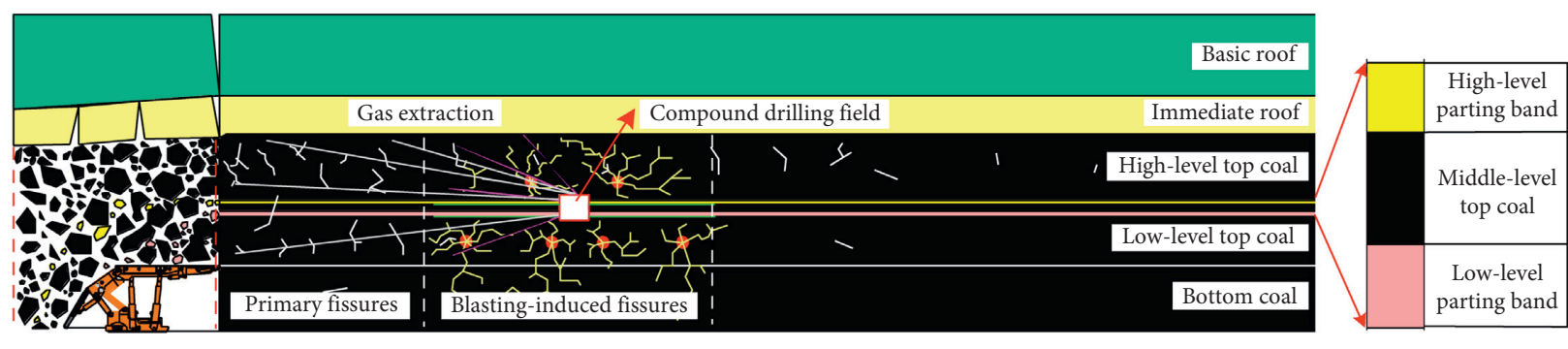

Top coal recovery zone

Drilling and blasting areas 1 and 2

Figure 14: Schematic diagram of extraction borehole arrangement.

used to observe construction boreholes following two processes for top coal weakening (e.g., in Figure 16(a)).

As can be found in borehole observation images (e.g., in Figure 16(c)), some radial fissures and annular fissures appeared inside boreholes after original top coal weakening process, though the fissures were not fully developed and failed to connect to each other. However, after specially designing the cyclic top coal weakening process, it is evident that a great number of radial fissures and annular fissures were present inside boreholes and the fissures were fully developed. In order to further evaluate extent of borehole fragmentation, the statistical analysis method for borehole fissures in "Basic Measurement Scale-Fragmentation Grading Evaluation" [50] was used, observation data were dealt with, and thereby curves of mean degree of borehole fragmentation after utilization of two top coal weakening 


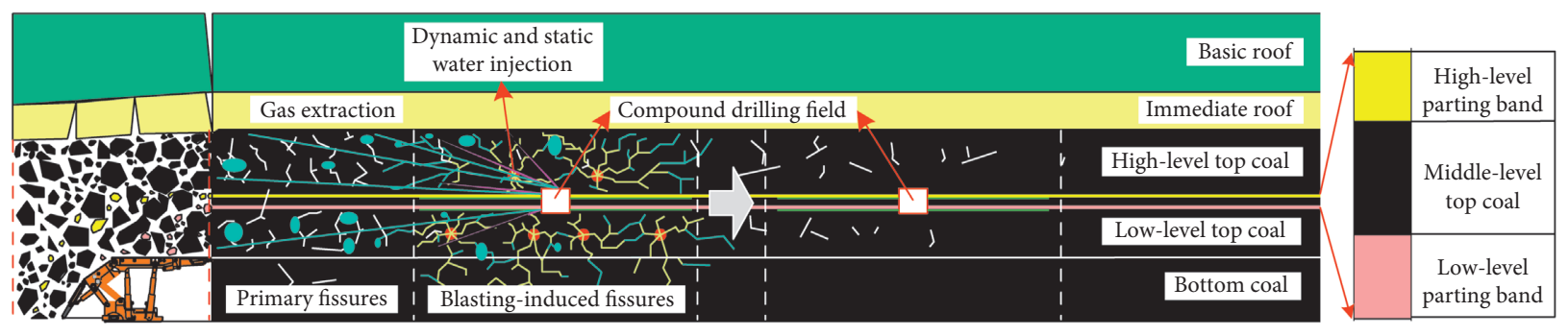

Top coal recovery zone

Drilling and blasting areas 1 and 2 Drilling and blasting areas 3 and 4

FIGURE 15: Schematic diagram of fissure development in the top coal weakened by dynamic and static water injection.

YTJ20 mine electronic borehole observation apparatus
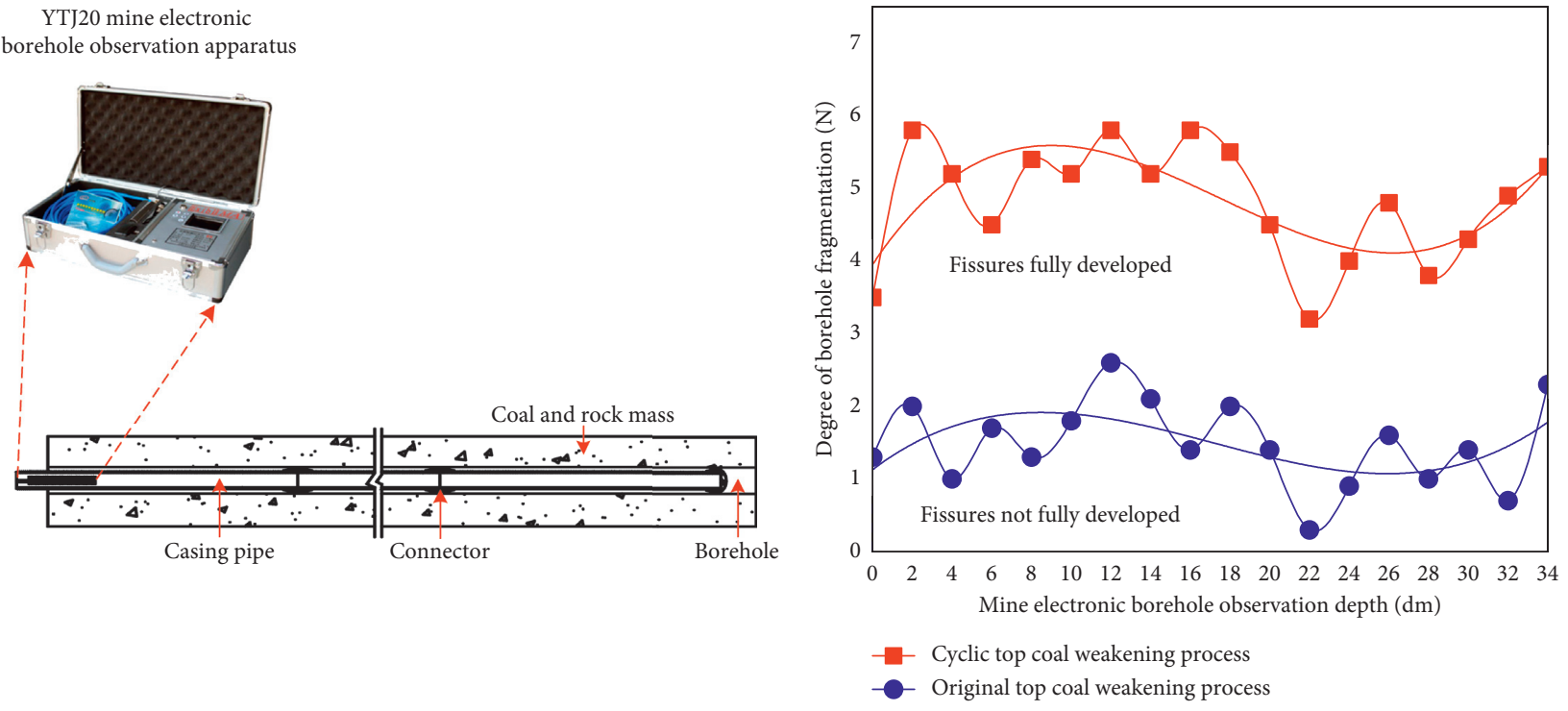

(a)
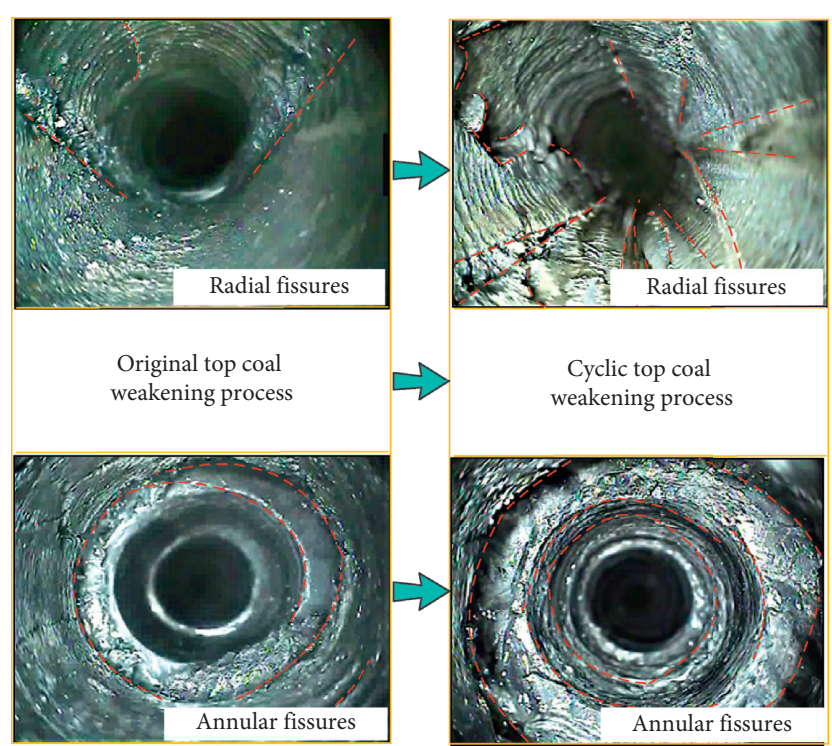

(c)

Figure 16: Evaluation for mean degree of borehole fragmentation and its results. (a) Mine electronic borehole observation apparatus and its installation. (b) Curves of mean degree of borehole fragmentation versus observation depth. (c) Comparison of observation images of fissures in different processes. 


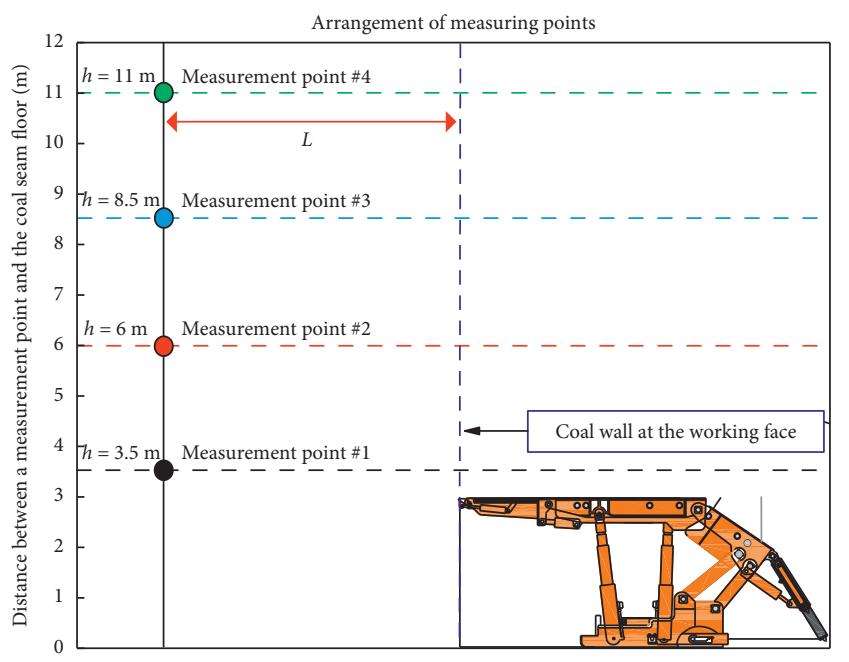

(a)

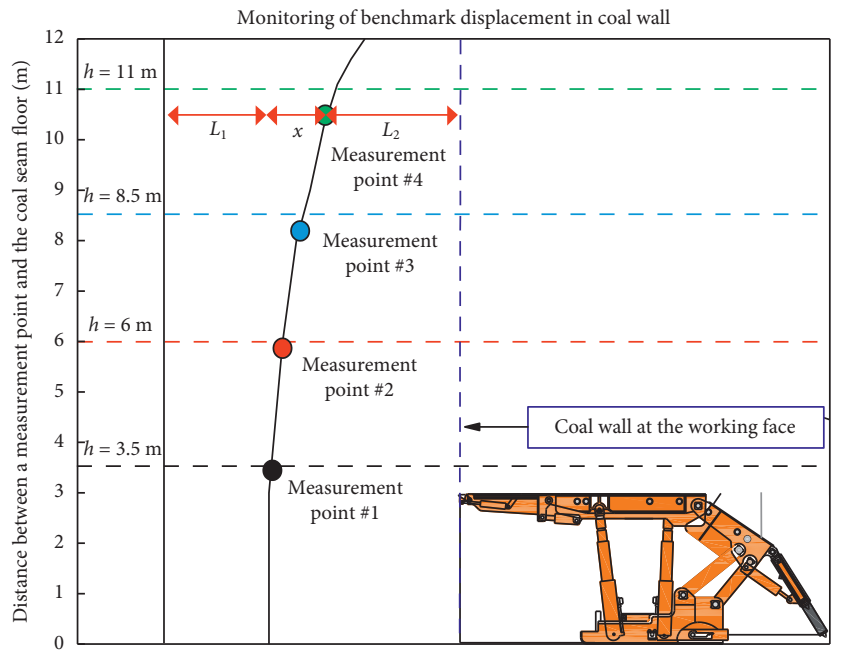

(c)

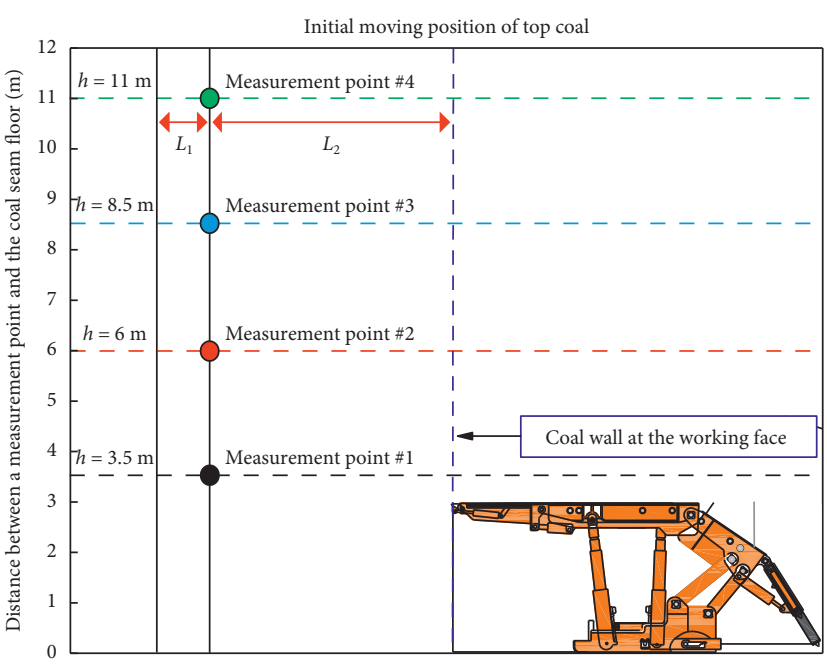

(b)

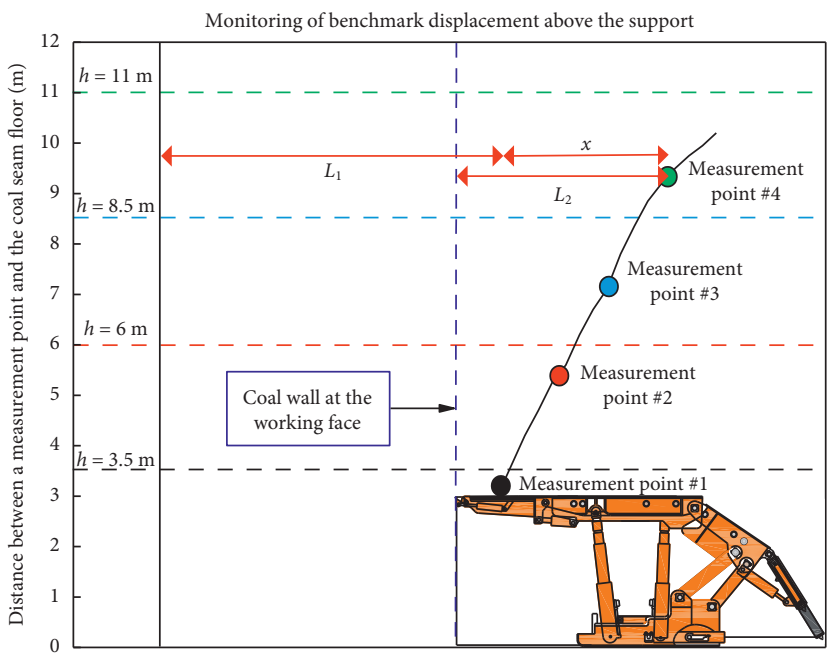

(d)

FIGURE 17: Acquisition method of horizontal benchmark displacement. (a) Arrangement of measurement points. (b) Initial moving position of top coal. (c) Monitoring of benchmark displacement in coal wall. (d) Monitoring of benchmark displacement above the support.

processes were obtained (e.g., in Figure 16(b)). It is found that the use of the cyclic top coal weakening process promoted significantly the development of fissures in top coal in comparison with the original top coal weakening process.

5.2. Cumulative Top Coal Displacement. Cumulative top coal displacement can be an indirect representation of the extent of fragmentation and lumpiness of top coal. Greater displacement indicates fragmentation to a greater extent and smaller broken lumps, and the top coal has excellent mobility and caves readily; otherwise, the top coal breaks incompletely [51]. For working face 110501 in Yushutian Coal Mine, field surveys of cumulative top coal displacement were carried out by deep benchmark displacement tracking [52] after the original top coal weakening process and cyclic top coal weakening process, respectively. Mean mining thickness of the observed coal seam was $9.5 \mathrm{~m}$, including a coal cutting height of $3 \mathrm{~m}$; measurement points were arranged at distances of $3.5 \mathrm{~m}, 6 \mathrm{~m}, 8.5 \mathrm{~m}$, and $11 \mathrm{~m}$ away from the coal seam floor, respectively (e.g., in Figure 17(a)), and curves of measured top coal and roof displacements (see Figure 18) were plotted, where the position at abscissa 0 is coal wall at the working face and $h$ is the distance between a measurement point and the coal seam floor. With the advancement of working face, the position where top coal begins to move is called initial moving point of top coal (e.g., in Figure 17(b)).

The horizontal displacement of measurement points in coal wall (e.g., in Figure 17(c)) and above the support (e.g., in Figure $17(\mathrm{~d})$ ) was monitored by deep benchmark displacement tracking. $L$ is the distance between measurement points and the coal wall at the working face when measurement points are arranged, $L_{1}$ is the advancing distance of the working face after the measurement points are arranged, and $L_{2}$ is the distance between the measurement points arranged and the coal wall at the working face at different times. 


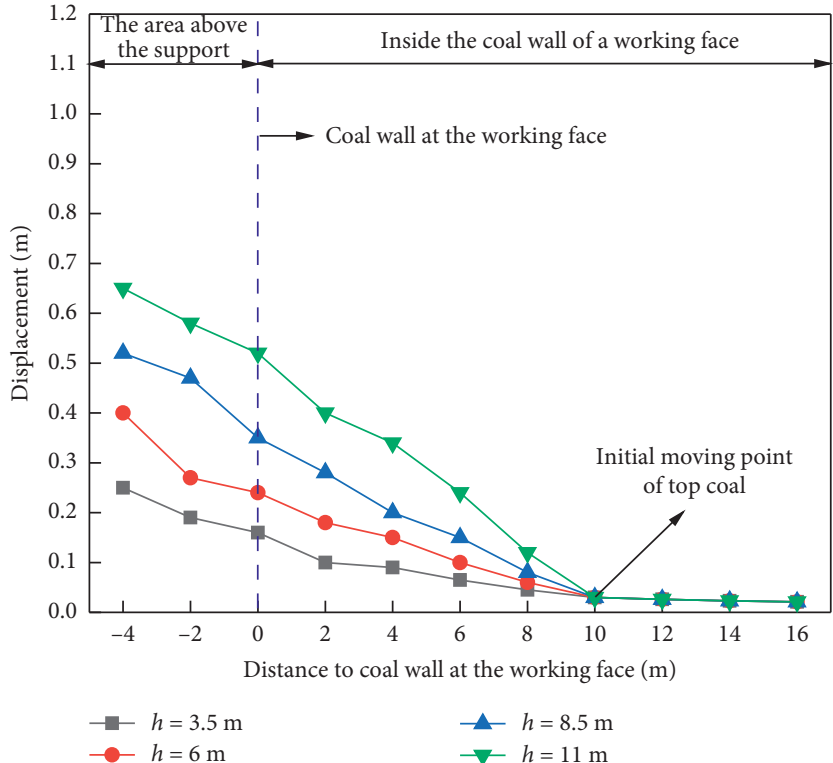

(a)

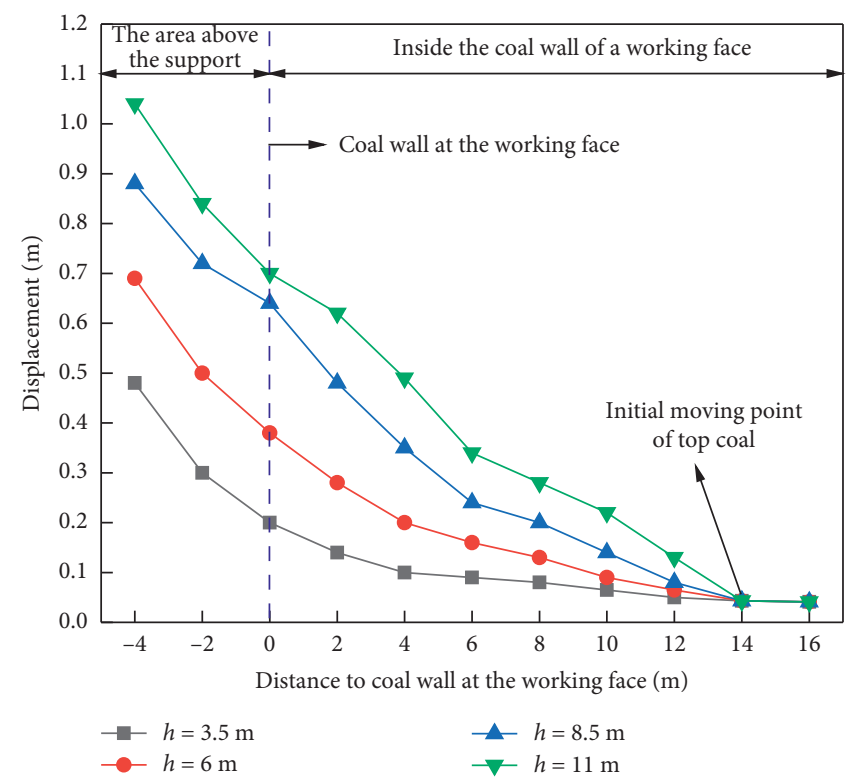

(b)

FIGURE 18: Curves of measured top coal and roof displacements in the (a) original top coal weakening process and (b) cyclic top coal weakening process.

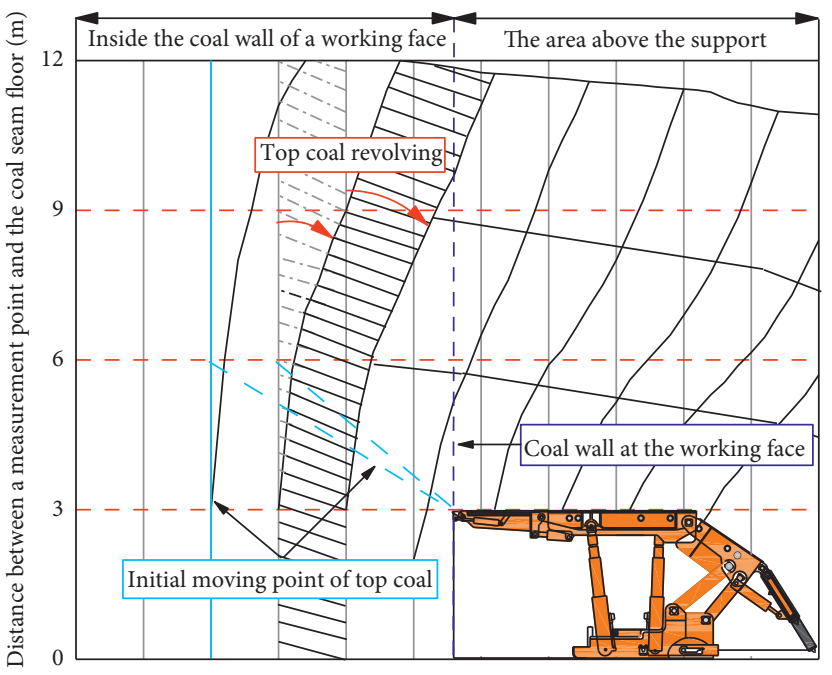

(a)

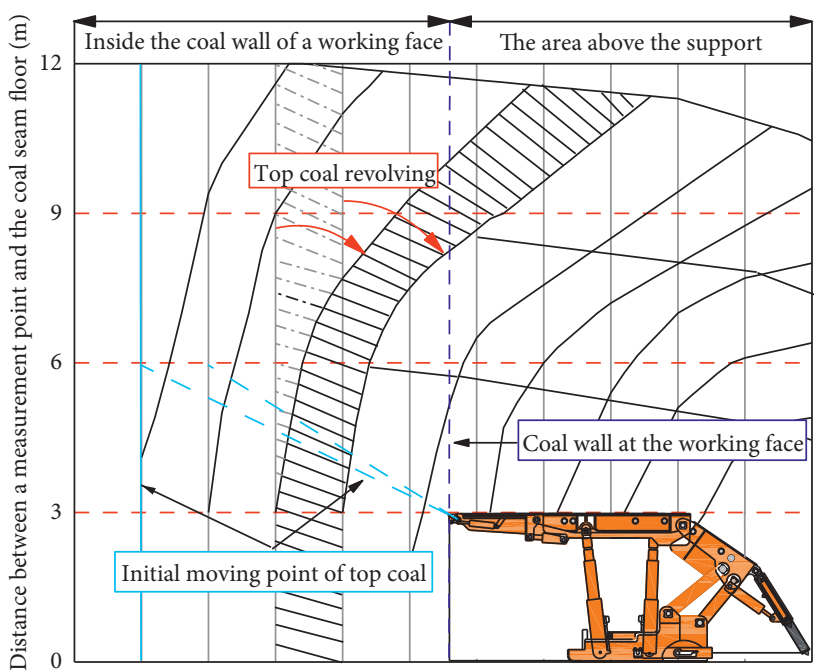

(b)

Figure 19: Top coal displacement field plots. Displacement field plot of top coal in the (a) original top coal weakening process and (b) cyclic top coal weakening process.

Horizontal benchmark displacement in coal wall (e.g., in Figure $17(\mathrm{c})$ ) can be obtained:

$$
x=L-L_{1}-L_{2} \text {. }
$$

Horizontal benchmark displacement of the top coal which is above the support (e.g., in Figure 17(d)) can be obtained:

$$
x=L_{2}-L_{1}+L
$$

The data in Figure 18 is the vertical displacement of each measurement point at different times. Based on displacement data and observation results of the top coal, displacement field plots of top coal after application of the two top coal weakening processes can be inferred [1] (Figure 19).

Figures 18 and 19 show that, after application of the original top coal weakening process, the top coal $10 \mathrm{~m}$ ahead of the working face began to move, and cumulative top coal displacements at 4 measurement points were all small; while 


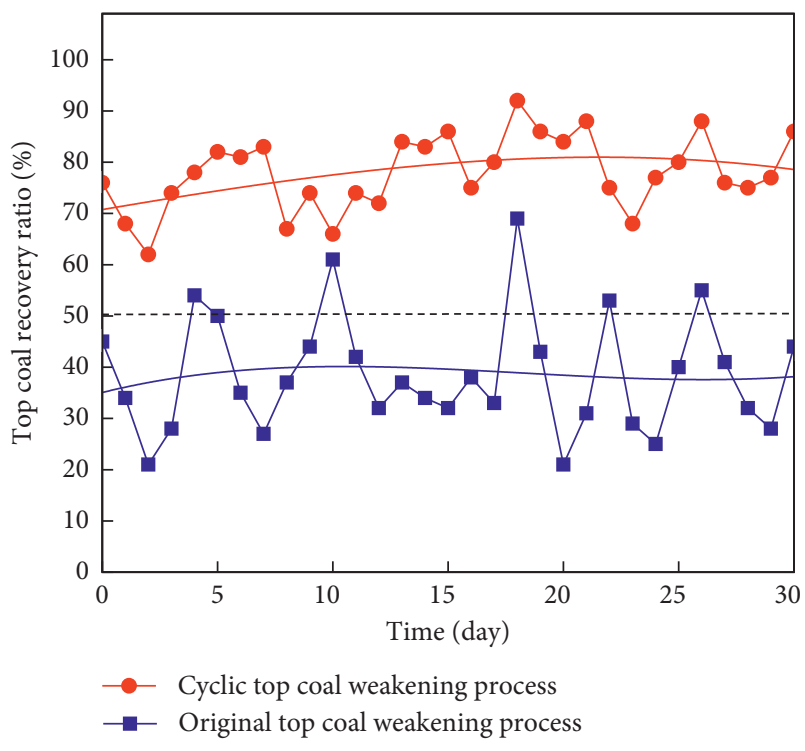

Figure 20: Top coal recovery ratios in different processes.

after application of cyclic top coal weakening process, the top coal $14 \mathrm{~m}$ ahead of the working face began to move, indicating good mobility of the top coal, and cumulative top coal displacements at all 4 measurement points increased significantly, demonstrating that this specially designed cyclic top coal weakening process enables full fragmentation of top coal and great improvement in top coal weakening performance and thus in more favor of top coal caving.

5.3. Top Coal Recovery Ratio. The top coal recovery ratio has immediate impact on production efficiency and coal output of a mine. For working face 110501 in Yushutian Coal Mine, the original top coal weakening process did not focus on high toughness and parting characteristics of the top coal; it only adopted the common deep-hole presplit blasting (e.g., in Figure 2(f)) and had no special design for the borehole arrangement, blasting parameters, and weakening method, resulting in low recovery ratio of top coal. Top coal recovery ratios in 30 days after application of the original top coal weakening process and cyclic top coal weakening process were statistically analyzed, respectively (Figure 20). Results show that, after the application of the cyclic top coal weakening process, the mean top coal recovery ratio could be up to $74 \%$ or so, higher by about $35 \%$ than that following the application of the original top coal weakening process, monthly coal output increased by about $27.5 \%$, top coal weakening performance was significantly improved, there were much fewer phenomena of coal resource waste, and coal output of the mine increased greatly.

\section{Conclusions}

At working face 110501 in Yushutian Coal Mine, it is very difficult to break and crush the highly tough top coal with partings, and it is difficult to weaken the top coal effectively by original top coal weakening process, resulting in a unique challenge for mine designers. Studies show that, two intrinsic factors of the top coal, namely, parting bands and high toughness, lead to poor cavability of the top coal itself. In this study, based on rationale of difficulty in top coal fragmentation, a target-oriented cyclic top coal weakening process has been proposed, and weakening performance has been evaluated in terms of three parameters. The following conclusions were obtained:

(1) Impact of parting band on fissure development in top coal was investigated by theoretical computing. Each parting band within the top coal at working face 110501 was simplified as a cantilever beam model under uniform load, and the modeling results indicate that it is difficult to break both parting bands because real thickness of each parting band is greater than respective critical thickness and the resulting cantilever structures support the top coal above respective partings. Furthermore, presence of parting bands will affect mobility of the top coal during caving because large lumps of caved coal lowered top coal cavability greatly.

(2) LS-DYNA was used to simulate numerically fissure development in the highly tough top coal weakened by blasting. The simulation results show that, after blast weakening, stress wave propagation velocity, fissure propagation velocity, pressure at model boundary, and crushing circle radius became lower due to high toughness of the top coal at working face 11050. Although fissures could propagate to the boundary after blast weakening, dominant fissures in the top coal were evidently fewer, secondary fissures grew more slowly, and the blast induced damage and fragmentation to lesser extents, making it difficult to weaken the top coal effectively.

(3) A special cyclic top coal weakening process for highly tough top coal with partings was proposed and applied in engineering practice. In this process, a multifunctional compound drilling field was designed to integrate blast weakening, water injection weakening, and gas extraction; full weakening of the top coal and rapid extraction of gas were achieved through steps such as compound drilling field arrangement, charging and detonation, rapid gas extraction, and dynamic and static water injection.

(4) Three parameters, namely, mean degree of borehole fragmentation, cumulative top coal displacement, and top coal recovery ratio, were used to check top coal weakening performance in order to better assess the application effect of the cyclic top coal weakening process. As a result, this process enabled effective improvement in the extent of top coal fragmentation, greater top coal mobility, and smaller lumps of caved coal; moreover, mean top coal recovery ratio of the working face rose by about $35 \%$, monthly coal output increased by about $27.5 \%$, and there were much fewer phenomena of coal resource waste, which brought good economic benefit and environmental 
benefit to the mine. In addition, this new cyclic top coal weakening process can be applied in other coal mines under similar geological conditions.

\section{Abbreviations}

$M_{A}$ : Moment of the cantilever beam

$q$ : Load applied on the cantilever beam

l: $\quad$ Cantilever length

$q_{1}$ : Load applied on the parting band

$q_{2}$ : Load applied on top coal above the parting band

$\sigma: \quad$ Tensile stress of the cantilever beam

$h$ : Thickness of the cantilever beam

$\sigma_{\text {max }}:$ The maximum tensile stress of the cantilever beam

$M_{\text {max }}$ : The maximum moment of the cantilever beam

$\gamma_{1}$ : Bulk density of the parting band

$h_{1}$ : Thickness of the parting band

$\gamma_{2}$ : Bulk density of the top coal

$h_{2}$ : Thickness of the top coal

$h_{\text {min }}$ : Critical thickness of the parting band

$R_{t}$ : Tensile strength of the parting

$E$ : $\quad$ Elastic modulus of the top coal.

\section{Data Availability}

The data used to support the findings of this study are available from the corresponding author upon request.

\section{Conflicts of Interest}

The authors declare no conflicts of interest regarding the publication of this paper.

\section{Authors' Contributions}

Zhaopeng $\mathrm{Wu}$ and Junhui Wang contributed equally to this work.

\section{Acknowledgments}

Zhaopeng $\mathrm{Wu}$ wants to particularly thank his parents for their support. This research was supported by the Fundamental Research Funds for the Central Universities (2017XKZD06).

\section{References}

[1] S. X. Hu, L. Q. Ma, J. S. Guo et al., "Support-surrounding rock relationship and top-coal movement laws in large dip angle fully-mechanized caving face," International Journal of Mining Science and Technology, vol. 28, no. 3, pp. 533-539, 2018.

[2] W. L. Shen, M. Wang, Z. Z. Cao et al., "Mining-induced failure criteria of interactional hard roof structures: a case study," Energies, vol. 12, no. 15, Article ID 3016, 2019.

[3] X. Z. Xie and T. L. Zhao, "Analysis on the top-coal caving structure of extra-thick hard coalseam with shallow depth in fully mechanized sublevel caving mining," Journal of China Coal Society, vol. 41, no. 2, pp. 359-366, 2016.
[4] Y. L. Wang, "Study and application of top coal in 215021 working face of Wangwa No. 2 mine," China Resources Comprehensive Utilization, vol. 35, no. 8, pp. 106-111, 2017.

[5] J. C. Wang, J. W. Zhang, S. L. Yang et al., "3-D movement law of top-coal in near horizontal coal seam with multi-gangue under caving mining technique," Journal of China Coal Society, vol. 40, no. 5, pp. 979-987, 2015.

[6] Y. F. Feng, Z. H. Ouyang, Z. G. Deng et al., “Analysis on top coal breaking mechanism of fully- mechanized caving mining face in ultra thick seam with parting," Coal Science \& Technology, vol. 44, no. 1, pp. 120-125, 2016.

[7] S. R. Pei, "Analysis of the impact of hard top-coal weakening on top coal mining," Energy \& Energy Conservation, vol. 2, pp. 57-59, 2017.

[8] X. Lai, P. Shan, J. Cao, H. Sun, Z. Suo, and F. Cui, "Hybrid assessment of pre-blasting weakening to horizontal section top coal caving (HSTCC) in steep and thick seams," International Journal of Mining Science and Technology, vol. 24, no. 1, pp. 31-37, 2014.

[9] Z. H. Wu and L. Yu, "Rational blast hole space of deep hole blasting for hard top-coal weakening," Coal Mining Technology, vol. 20, no. 4, pp. 107-110, 2015.

[10] B. Huang, Y. Wang, and S. Cao, "Cavability control by hydraulic fracturing for top coal caving in hard thick coal seams," International Journal of Rock Mechanics and Mining Sciences, vol. 74, pp. 45-57, 2015.

[11] B. Xia, X. Zhang, B. Yu, and J. Jia, "Weakening effects of hydraulic fracture in hard roof under the influence of stress arch," International Journal of Mining Science and Technology, vol. 28, no. 6, pp. 951-958, 2018.

[12] J. Li, B. Jia, C. Zhang, and W. Wang, "Seepage mechanism technical practice of hydraulic fracturing of coal seam and auxiliary image simulation technology," Journal of Visual Communication and Image Representation, vol. 59, pp. 244-252, 2019.

[13] N. Zhang and C. Liu, "Arch structure effect of the coal gangue flow of the fully mechanized caving in special thick coal seam and its impact on the loss of top coal," International Journal of Mining Science and Technology, vol. 26, no. 4, pp. 593-599, 2016.

[14] W. Q. Ma, T. X. Wang, and K. Ma, "Study on difficult falling mechanism and weakening effect of fully-mechanized top coal caving mining in high ductibility seam," Coal Science \& Technology, vol. 43, no. 10, pp. 56-60, 2019.

[15] W. Q. Ma, T. X. Wang, and K. D. Qu, "Analysis on difficult caving mechanism of high toughness coal seam based on thin plate model," Journal of Mining \& Safety Engineering, vol. 34, no. 4, pp. 644-649, 2017.

[16] L. S. Zhao, "Power ultrasound-induced heating mechanism of gas in coal seam," Journal of Liaoning Technical University, vol. 29, no. 1, pp. 17-19, 2010.

[17] J. L. Liao, W. J. Liu, W. Q. Wang et al., "Study on mechanism and technology of top coal weakening in "two hard" fully mechanized coal seam caving mining," Journal of North China Institute of Science \& Technology, vol. 12, no. 4, pp. 20-24, 2015.

[18] Y. B. Pan and Z. G. Liu, "Application of deep hole pre-split blasting technology in weakening of dirt band," Journal of Safety Science \& Technology, vol. 9, no. 9, pp. 107-110, 2013.

[19] Y. F. Feng, "Research on weakening technology of hard dirt band presplitting blasting based on LS-DYNA," Chinese Journal of Underground Space \& Engineering, vol. 12, no. S2, pp. 726-732, 2016.

[20] L. Si, Z. Li, and Y. Yang, "Coal permeability evolution with the interaction between nanopore and fracture: its application in 
coal mine gas drainage for Qingdong coal mine in Huaibei coalfield, China," Journal of Natural Gas Science and Engineering, vol. 56, pp. 523-535, 2018.

[21] J. Liu, Z. G. Liu, K. Gao et al., "Application of deep borehole blasting to top-coal pre-weakening and gas extraction in fully mechanized caving," Chinese Journal of Rock Mechanics \& Engineering, vol. 33, no. S1, pp. 3361-3367, 2014.

[22] Y. Zhao, B. Q. Lin, T. Liu et al., "Gas flow in hydraulic slottingdisturbed coal seam considering stress relief induced damage," Journal of Natural Gas Science and Engineering, vol. 75, Article ID 103160, 2020.

[23] K. Z. Zhang, Y. P. Cheng, L. Wang et al., "Pore morphology characterization and its effect on methane desorption in water-containing coal: an exploratory study on the mechanism of gas migration in water-injected coal seam," Journal of Natural Gas Ence and Engineering, vol. 75, Article ID 103152, 2020.

[24] W. Yang, H. Wang, Q. Zhuo et al., "Mechanism of water inhibiting gas outburst and the field experiment of coal seam infusion promoted by blasting," Fuel, vol. 251, pp. 383-393, 2019.

[25] G. H. Ni, K. Dong, S. Li et al., "Gas desorption characteristics effected by the pulsating hydraulic fracturing in coal," Fuel, vol. 236, pp. 190-200, 2019.

[26] Z. G. Xiao and Z. F. Wang, "Experimental study on inhibitory effect of gas desorption by injecting water into coal-sample," Procedia Engineering, vol. 26, pp. 1287-1295, 2011.

[27] W. G. Jiang, "Study on law and comprehensive prevention technology of residual coal oxidation in fully mechanized caving face with "one face and four tunnels"” China Mining Magazine, vol. 28, no. S1, pp. 284-288, 2019.

[28] W. Yang, M. Lin, G. Walton et al., "Blasting-enhanced water injection for coal and gas out-burst control," Process Safety and Environmental Protection, vol. 140, pp. 233-243, 2020.

[29] K. Gao, S. N. Li, R. Han et al., "Study on the propagation law of gas explosion in the space based on the goaf characteristic of coal mine," Safety Science, vol. 127, Article ID 104693, 2020.

[30] J. L. Xu and M. G. Qian, "Method to distinguish key strata in overburden," Journal of China University of Mining \& Technology, vol. 29, no. 5, pp. 463-467, 2000.

[31] W. Zhu and Y. H. Teng, "Characteristic of development of the fractured zone in mining under medium hard overburden using fully-mechanized top-coal caving method," Applied Mechanics and Materials, vol. 226-228, pp. 1312-1317, 2012.

[32] D. F. Zhu, X. M. Song, H. C. Li et al., "“Cooperative loadbearing characteristics of a pillar group and a gob pile in partially caved areas at shallow depth," Energy Ence \& Engineering, vol. 8, no. 7, pp. 89-103, 2019.

[33] F. Wang, S. Tu, Y. Yuan, Y. Feng, F. Chen, and H. Tu, “Deephole pre-split blasting mechanism and its application for controlled roof caving in shallow depth seams," International Journal of Rock Mechanics and Mining Sciences, vol. 64, pp. 112-121, 2013.

[34] C. R. Li, L. J. Kang, Q. X. Qi et al., "The numerical analysis of borehole blasting and application in coal mine roof-weaken," Procedia Earth \& Planetary Science, vol. 1, no. 1, pp. 451-459, 2009.

[35] Z. Zhou, C. Q. Zhu, Q. F. Li et al., "The mined rock mass movement law considering the properties of coal seam," Chinese Journal of Underground Space \& Engineering, vol. 13, no. 5, pp. 1338-1346, 2017.

[36] J. Zhang, W. Yang, B. Lin, J. Zhang, and M. Wang, "Strata movement and stress evolution when mining two overlapping panels affected by hard stratum," International Journal of
Mining Science and Technology, vol. 29, no. 5, pp. 691-699, 2019.

[37] J. H. Wen, W. M. Cheng, L. J. Chen et al., "A study of the dynamic movement rule of overlying strata combinations using a short-wall continuous mining and full-caving method," Energy Science \& Engineering, vol. 7, no. 7, pp. 1-21, 2019.

[38] D. Zhu, S. Tu, H. Tu, and Z. Yang, "Mechanisms of support failure and prevention measures under double-layer room mining gobs - a case study: Shigetai coal mine," International Journal of Mining Science and Technology, vol. 29, no. 6, pp. 955-962, 2019.

[39] C. Gao, N. Z. Xu, and B. Q. He, "Study on influence of key strata on surface subsidence law of fully-mechanized caving mining in extra-thick coal seam," Coal Science and Technology, vol. 47, no. 9, pp. 229-234, 2019.

[40] D. F. Zhu, Y. H. Wu, Z. H. Liu et al., "Failure mechanism and safety control strategy for laminated roof of wide-span roadway," Engineering Failure Analysis, vol. 111, Article ID 104489, 2020.

[41] X. J. Gao, H. Y. Yu, Z. Z. Huang et al., "Research on directional hydraulic fracturing between powered support to improve top coal caving property in extreme thick seam with parting," Coal Ence ed Technology, vol. 45, no. 3, pp. 56-61, 2017.

[42] W.-F. Zhang, Y.-C. Liu, G.-L. Hou et al., "Lateral-torsional buckling analysis of cantilever beam with tip lateral elastic brace under uniform and concentrated load," International Journal of Steel Structures, vol. 16, no. 4, pp. 1161-1173, 2016.

[43] E. Barbieri, "Analytical solution of the cantilevered elastica subjected to a normal uniformly distributed follower load," International Journal of Solids and Structures, vol. 202, pp. 486-494, 2020.

[44] D. Y. Guo, C. Zhang, T. G. Zhu et al., "Effect of charge structure on deep-hole cumulative blasting to improve coal seam permeability," Chinese Journal of Engineering, vol. 40, no. 12, pp. 1488-1494, 2018.

[45] Q. Ye, Z. Jia, and C. Zheng, "Study on hydraulic-controlled blasting technology for pressure relief and permeability improvement in a deep hole," Journal of Petroleum Science and Engineering, vol. 159, pp. 433-442, 2017.

[46] R. F. Huang, Z. G. Zhang, and B. Cheng, "Study on control mechanism and method of gas concentration ingas drainage borehole of underground mine," Coal Science and Technology, vol. 45, no. 5, pp. 128-135, 2017.

[47] G. Zhang, J. G. Wu, and L. J. Yang, "Determination of the sealing length of upward long crossing boreholes for gas drainage under unequal stress fields," Chinese Journal of Rock Mechanics \& Engineering, vol. 37, no. S1, pp. 3422-3431, 2018.

[48] X. M. Lou, Z. C. Wang, B. G. Chen et al., "Initial shock pressure analysis for hole wall with air-decked charge," Journal of China Coal Society, vol. 42, no. 11, pp. 2875-2884, 2017.

[49] T. H. Yang, T. Xu, H. Y. Liu, C. A. Tang, B. M. Shi, and Q. X. Yu, "Stress-damage-flow coupling model and its application to pressure relief coal bed methane in deep coal seam," International Journal of Coal Geology, vol. 86, no. 4, pp. 357-366, 2011.

[50] H. W. Zhang, Z. J. Wan, Y. Zhang et al., "Deformation mechanism of narrow coal pillar in the fully-mechanized gobside entry with incompletely stable overlying strata," Journal of Mining and Safety Engineering, vol. 33, no. 4, pp. 692-698, 2016.

[51] W.-l. Shen, J.-b. Bai, W.-f. Li, and X.-y. Wang, "Prediction of relative displacement for entry roof with weak plane under the 
effect of mining abutment stress," Tunnelling and Underground Space Technology, vol. 71, pp. 309-317, 2018.

[52] X. B. Duan, Q. Z. Tian, and S. Guo, "In-site measurement and research of top-coal movement law for fully mechanized topcoal caving face in inclined slice of extra-thick coal seam," Mining Research \& Development, vol. 33, no. 4, pp. 7-9, 2013. 